\title{
Aging and Inhibition: Beyond a Unitary View of Inhibitory Processing in Attention
}

\author{
Arthur F. Kramer, Darryl G. Humphrey, John F. Larish, \\ Gordon D. Logan, and David L. Strayer
}

\begin{abstract}
The authors examined the question of whether a decrease in the efficiency of inhibitory processing with aging is a general phenomenon. Thirty elderly and 32 young adults performed a series of tasks from which the authors could extract measures of inhibitory function. The tasks and task components included response compatibility, negative priming, stopping, spatial precuing, Wisconsin Card Sorting Test (WCST), and the Cognitive Failures Questionnaire (CFQ). Only limited evidence for age-related differences in inhibitory function was obtained. Old adults had more difficulty than young adults in stopping an overt response and adopting new rules in a categorization task. However, elderly and young adults produced equivalent negative priming effects, response compatibility effects, spatial precuing effects, and self-reported cognitive failures. The findings are discussed in terms of the relationship between aging, inhibitory processes, and neuroanatomical and physiological function.
\end{abstract}

A dominant view in the aging literature is that cognitive decline in later life is the result of a progressive and generalized slowing of information-processing activities (Birren, 1974; Cerella, 1990; Salthouse, 1992). Much of the evidence for such a view has been provided through reanalyses of existing data sets (Cerella, 1985b; Myerson, Hale, Wagstaff, Poon, \& Smith, 1991; Salthouse, 1985). Examination of large numbers of tasks has suggested that reaction times (RTs) of elderly subjects can be described as simple linear or nonlinear functions of young subjects' RTs, without reference to the specific nature of the tasks. Although this generalized-slowing view provides a good account of RT data in a multitude of studies (but see Baron \& Mattila, 1989; Fisk, Fisher, \& Rogers, 1992), such a view has, for the most part, been descriptive rather than theoretical in nature (but see Cerella, 1990).

An important question is what processes or mechanisms are responsible for this generalized slowing that occurs during aging? One relatively recent proposal that could provide the theoretical basis for generalized slowing concerns inhibitory function. Hasher and Zacks (1988; see also Zacks \& Hasher, in press) suggested that age-related processing deficits in a variety of cog-

Arthur F. Kramer, Darryl G. Humphrey, John F. Larish, and Gordon D. Logan, Department of Psychology and Beckman Institute, University of Illinois; David L. Strayer, Department of Psychology, University of Utah.

This research was supported by the National Institute of Aging Grant AGO8435. Portions of this work were presented at the 1992 Cognitive Aging Conference in Atlanta, Georgia.

We are indebted to Susan Gass for assistance in data collection, with special thanks to Heather Pringle for her invaluable assistance in data management and project organization. We express our appreciation to Tram Neill and Joan McDowd for their helpful comments on a draft of this article.

Correspondence concerning this article should be addressed to Arthur F. Kramer, Beckman Institute, University of Illinois, 405 North Mathews Avenue, Urbana, Illinois 61801. nitive skills could be accounted for by a decrease in the efficiency of inhibitory processing during aging. More specifically, inefficient inhibition could result in ineffective selective attention, which could, in turn, result in the intrusion of task irrelevant information into working memory. The consequences of the entrance of irrelevant information into working memory may include both increased processing time and reductions in recognition and recall of relevant information.

Hasher and Zacks' (1988) model is consistent with a variety of studies that have found age-related differences in attention and memory. For example, a number of investigators have examined age-related differences in the Stroop (1935) paradigm. In this task, subjects are asked to name the color of the ink in which a word is presented. On some trials, the word and ink color are congruent, such as the word red presented in red ink. On other trials, the relationship between the word and the ink color is incongruent, such as the word red in blue ink. Although subjects are instructed to name the ink color and ignore word meaning, RTs are usually elevated in the incongruent relative to the congruent condition. Although there is still some controversy regarding the processing mechanisms responsible for the Stroop effect, there is relatively strong evidence that a substantial portion of the interference is the result of response competition (MacLeod, 1991). A number of researchers have found that old adults produce a larger RT difference between the congruent and incongruent conditions than young subjects (N. Cohen, Dustman, \& Bradford, 1984; Comalli, Wapner, \& Werner, 1962; Houx, Jolles, \& Vreeling, 1993; see also Rogers \& Fisk, 1991). These findings have been interpreted in terms of increased susceptibility to interference from irrelevant information during aging.

Findings obtained in the negative priming paradigm also suggest that old adults have more difficulty inhibiting irrelevant information than do young adults. In this paradigm, subjects are asked to respond to targets and ignore simultaneously presented distractor stimuli. On some trials, a distractor from trial 
$n-1$ (prime trial) becomes a target on trial $n$ (probe trial). This is usually referred to as an ignored repetition (IR) condition. In the control condition, there is no relationship between targets and distractors on the prime and probe trials. In general, longer RTs have been obtained in the IR than in the control conditions for a variety of stimuli including letters (Neill \& Valdes, 1992; Tipper \& Cranston, 1985), words (Lowe, 1985; Neill, 1977; Yee, 1991), pictures (Tipper \& Driver, 1988), and novel geometric patterns (DeSchepper \& Treisman, 1991). This phenomenon has been referred to as negative priming (Tipper, 1985) to reflect the inhibitory effects of the ignored stimuli. Although the theoretical underpinnings of negative priming are still being debated, the modal view is that the longer RT in the IR condition is the result of reduced access to the response mechanisms for the ignored distractors (Neill, 1989; Tipper \& Cranston, 1985).

Hasher, Stoltzfus, Zacks, and Rypma (1991) compared young and elderly adults' performance in a letter-naming task in which subjects were instructed to respond to a target and ignore a color-coded distractor. Young subjects showed negative priming in two experiments that differed in response-stimulus interval. Old adults failed to produce negative priming in either of the experiments. Similar results have been obtained by other investigators in letter (McDowd \& Oseas-Kreger, 1991; Stoltzfus, Hasher, Zacks, Ulivi, \& Goldstein, 1993), word (Kane, Hasher, Stoltzfus, Zacks, \& Connelly, 1994), and picture-naming tasks (Tipper, 1991). Like the age-related differences in Stroop performance, these results have been taken as support for Hasher and Zacks's (1988) model of a generalized reduction in the efficiency of inhibitory processing during aging.

In fact, in addition to the evidence obtained in the Stroop and negative priming paradigms, there is extensive support in other paradigms for decreased inhibitory function during aging. Old adults have been found to show less habituation to irrelevant stimuli than do young adults (McDowd \& Filion, 1992), larger disruptions in RT with increasing number of distractors in visual search than do young adults (Fisk \& Rogers, 1991; Madden, 1983; Scialfa, Kline, \& Lyman, 1987), less flexibility in acquiring new rules in concept formation tasks than do young adults (Haaland, Vranes, Goodwin, \& Garry, 1987), more intrusion of irrelevant information during text comprehension than do young adults (G. Cohen, 1988), and reduced ability to inhibit well-learned response patterns during the acquisition of new response patterns than do young adults (Kausler \& Hakami, 1982). Each of these age-related performance differences can be interpreted in terms of increased susceptibility to interference and decreased inhibitory function for elderly adults.

These results provide impressive support for Hasher and Zacks's (1988) proposal of decreased inhibitory function in elderly adults. However, an important question, and the central focus of the present study, is whether these findings are consistent with the failure of a general inhibitory mechanism, as suggested by Hasher and Zacks, or whether age-related performance differences might be better explained by more specific and limited failures in a subset of inhibitory processes. Of course, the latter hypothesis requires the specification of the inhibitory mechanisms, which are and are not susceptible to aging.

One way to begin to address this question is to consider the results of studies that have failed to find age-related perfor- mance differences in tasks in which inhibitory processes can be argued to be operating. Two different variants of the negative priming paradigm have been examined with respect to aging. In the version described above, subjects responded to the identity of the targets. However, another version of the negative priming paradigm requires subjects to respond to the location of a stimulus rather than its identity (Tipper, Brehaut, \& Driver, 1990). In this case, equivalent negative priming effects have been found for both young and elderly adults (Connelly \& Hasher, 1992, 1993; Filion, McDowd, \& Baylis, 1992).

Evidence of equivalent inhibitory effects for young and elderly adults has also been provided in studies that have examined the inhibition of return (IOR) phenomenon (Kieley \& Hartley, 1990). IOR has been defined in terms of longer RTs when a stimulus occurs in the same spatial position on temporally contiguous trials as compared with situations in which the position of the stimulus varies over trials (Maylor \& Hockey, 1985, 1987; Posner, Rafal, Choate, \& Vaughan, 1985). Posner and Cohen (1984) have suggested that IOR is one of the methods by which the nervous system favors novel information over previously encoded information.

Finally, there is also substantial evidence that elderly and young adults show the same pattern of performance when required to shift attention among different locations in the visual field on the basis of precues (Hartley, 1992; Hartley, Kieley, \& Slabach, 1990; Nissen \& Corkin, 1985). Similarly, Hartley, Kieley, and McKenzie (1992) have found that young and elderly adults are equally facile at expanding and contracting attention within a limited region of the visual field. To the extent that attention is likened to a zoom lens in which the processing of stimuli that fall within the boundaries of the lens are facilitated and stimuli that fall outside of the lens are inhibited (Pan \& Eriksen, 1993), these results provide additional support for sparing of inhibitory function during aging.

On the basis of the literature reviewed above, it appears conceivable that aging may be associated with selective rather than general decreases in inhibitory function. An important question, however, is whether there is a theoretical framework that can account for selective deficits of inhibitory functioning during aging. Two theoretical proposals have been offered to account for selective deficits in inhibitory function. On the basis of findings that old adults show negative priming effects in location but not in identity judgment tasks, Connelly and Hasher (1993) suggested that separate inhibitory mechanisms might subserve these two judgments and that inhibition of location might be relatively insensitive to aging. In fact, there is strong anatomical and physiological evidence for separate neural pathways that support the processing of location ("where" system), the dorsal or occipitoparietal pathway, and the detailed processing of objects ("what" system), the ventral or occipitotemporal pathway (Merigan \& Maunsell, 1993; Ungerleider \& Mishkin, 1982). Furthermore, there is now substantial evidence that components of each of these pathways reflect attentional processes. For example, damage to the posterior parietal lobe, a component of the dorsal pathway, results in difficulty in disengaging attention from targets that are contralateral to the side of the lesion (Posner, Walker, Friedrich, \& Rafal, 1987). Enhanced firing rates for single cells in the parietal lobe of monkeys have been obtained when attention is covertly directed to a target 
location (Bushnell, Goldberg, \& Robinson, 1981). Similar types of evidence have been provided for attentional effects in the ventral pathway. For instance, Corbetta, Miezin, Dobmeyer, Shulman, and Petersen (1991) found increases in activation in temporal cortex, via measures obtained through positron emission tomography (PET), when subjects were asked to selectively process stimuli that differed in shape. Chelazzi, Miller, Duncan, and Desimone (1993) found enhancements in single cells located in the inferior temporal cortex when monkeys searched visual arrays for complex target pictures.

In addition to the neuroanatomical and physiological evidence for distinct visual pathways, Connelly and Hasher's (1993) proposal gains support from studies, reviewed above, that have failed to find age-related differences in IOR and tasks that require subjects to expand or contract their focus of attention. Both of these tasks require the processing of locational information and therefore can be argued to rely, in part, on the dorsal visual pathway. Finally, there is some evidence that the integrity of the temporal lobes, one of the components of the ventral visual pathway, is compromised during aging. Signifcant declines in cerebral blood flow to the inferior temporal lobes have been reported for elderly adults. However, these declines in blood flow are approximately of the same magnitude as those found in parietal regions, a component of the dorsal visual system (T. Shaw et al., 1984). In summary, Connelly and Hasher's (1993) proposal for selective sparing of inhibitory function during aging has received positive but limited support in behavioral paradigms and from studies of cerebral blood flow.

A second proposal for limited sparing of inhibitory function during aging is based on both a neurocognitive model of attention and evidence of selective neuroanatomical and physiological changes that accompany aging. Dempster (1992), Hartley (1993), and Arbuckle and Gold (1993) have independently proposed that age-related differences in inhibitory function will be observed to the extent that performance depends on the integrity of the frontal lobes. The justification for this proposal is twofold. First, there is extensive neuroanatomical, physiological, and neuropsychological evidence that frontal lobe function is more susceptible to normal aging than are other regions of the brain. For example, reductions in cerebral blood flow occur earlier and are more pronounced in the frontal lobes than they are in other brain regions (Gur, Gur, Obrist, Skolnick, \& Reivitch, 1987; T. Shaw et al., 1984; Warren, Butler, Katholi, \& Halsey, 1985). Furthermore, studies that examine loss of neural tissue in various brain regions suggest that such changes are most prominent in the frontal lobes and the regions to which they connect, the basal ganglia and the thalamus (Haug et al., 1983; Scheibel \& Scheibel, 1975). Finally, a number of studies have found larger age-related decrements in tasks that are sensitive to frontal lobe function than tasks that are sensitive to the processing associated with other brain regions (Arbuckle \& Gold, 1993; Loranger \& Misiak, 1960; Whelihan \& Lesher, 1985).

The link between frontal lobe function and attentional processes, including those processes that reflect inhibitory function, is provided by a model proposed by Posner and colleagues (Posner, 1992; Posner \& Petersen, 1990). Posner argued that there are two distinct attentional systems, a posterior and an anterior system. The posterior system includes structures such as the parietal cortex, the pulvinar nucleus of the thalamus, and the superior colliculus. This system is responsible for orienting to stimuli on the basis of attributes such as location, color, shape, and movement. In fact, it has been suggested that the pulvinar functions as an attentional filter that distinguishes relevant from irrelevant stimuli on the basis of physical attributes (LaBerge, 1992; LaBerge \& Buchsbaum, 1990). Thus, this system integrates aspects of the ventral and dorsal visual systems, which serve as the neuroanatomical basis of the Connelly and Hasher (1993) proposal. The second component of Posner's model is the anterior attention network. This system is mainly composed of regions within the frontal lobes, including the anterior cingulate, prefrontal area, and supplemental motor areas. This system is responsible for executive functions such as planning, coordinating the processing of multiple streams of information, the initiation and stopping of behaviors, and the processing of semantic information.

The proposal that age-related differences in inhibitory function will be observed to the extent that performance depends on the integrity of the frontal lobes is consistent with the findings, reviewed above, that suggest that old adults show more intrusion of irrelevant information during text processing (G. Cohen, 1988), have difficulty inhibiting old response patterns when attempting to learn new ones (Kausler \& Hakami, 1982), and make more perseverative errors when required to learn new rules to categorize stimulus patterns (Haaland et al., 1987). The frontal lobe model can also account for the failure to find agerelated differences in tasks that involve the IOR effect and location-based negative priming because these processes can be argued to take place in the posterior attentional system.

In summary, two proposals have been offered to account for selective deficits in inhibitory function during aging. The Connelly and Hasher (1993) model, based on the distinction between the dorsal (where) and ventral (what) visual pathways, provides a good account of performance in the location and identity-based negative priming tasks and predicts preserved inhibitory function in situations in which location judgments are involved, such as the IOR effect. The disadvantage of this model is that it is limited to making predictions about the aspects of visual processing that take place in the dorsal and ventral visual pathways rather than incorporating more wide-ranging mechanisms responsible for functions such as task coordination, multimodal processing, and the initiation and cessation of behaviors.

The frontal lobe model (Arbuckle \& Gold, 1993; Dempster, 1992; Hartley, 1993) accounts well for age-related inhibitory failures in a wide variety of domains such at text processing, motor learning, and concept acquisition. The model also correctly predicts sparing of function during spatial attention operations. Finally, the model is well supported by neurophysiological and anatomical data, which suggests that the frontal lobes are compromised by aging to a greater extent than other brain regions. Conversely, the model appears inconsistent with the finding of age-related differences in identity-based negative priming to the extent that the inhibitory mechanism that subserves this effect is located outside of the frontal lobes.

Of course, another possibility is that there are multiple inhibitory mechanisms, for example, mechanisms subserved by the 
dorsal and ventral visual pathways as well as the frontal lobes, and that these mechanisms might be differentially influenced by normal aging. Thus, it is conceivable that both the dorsalventral and frontal models are partially correct in positing selective deficits in inhibitory function during aging. In this case, it might be expected that age-related inhibitory deficits would be found in tasks subserved by either the ventral visual pathway or the frontal lobes.

\section{Experimental Overview}

Two major issues were investigated in our study. First, we wished to determine whether age-related inhibitory failures are general or specific in nature. Above, we presented a modest amount of evidence that suggests that age-related inhibitory failures may be limited to a subset of inhibitory processes. However, it is important to note that the great majority of evidence that has been used in support of the specificity argument has been gathered in separate studies with different populations of subjects (for exceptions, see Arbuckle \& Gold, 1993; Connelly \& Hasher, 1993; Hartley, 1993; Kane et al., 1994). Much stronger evidence for the specificity hypothesis would be provided if the same group of young and elderly adults were examined in a variety of different paradigms that tapped arguably different inhibitory mechanisms. To this end, we have tested a modest number of young and elderly adults (e.g., 32 young and 30 elderly subjects) in a variety of attentional tasks. The important question here is whether significant within-subject associations among measures of inhibitory function can be demonstrated across different tasks and stimuli. Such a demonstration would provide evidence for a general inhibitory component.

The second major issue presupposes that there is at least some degree of specificity of inhibitory function and that some inhibitory processes are relatively immune to aging. Given these assumptions, it is important to determine the extent to which existing models of aging and inhibition, such as the dorsal-ventral model (Connelly \& Hasher, 1993) and the frontal lobe model (Arbuckle \& Gold, 1993; Dempster, 1992; Hartley, 1993), can account for the data. We have examined this issue by administering a number of tasks from which we can infer inhibitory processes that rely, in part, on either the dorsal or ventral visual pathways or the frontal regions of the brain. Of course, the mapping of human information-processing activities inferred from behavioral paradigms to brain regions is at best an inexact endeavor. However, we believe that there is now sufficient data available from human PET and lesion studies as well as singlecell recordings in animals to begin to justify a cognitive neuroscience approach to aging.

One task that we have included in our battery has been well validated as a measure of frontal lobe function. Performance on the Wisconsin Card Sorting Test (WCST), particularly measures of perseverative errors, has been found to be associated with frontal lobe lesions in human patients (Drewe, 1974; Heaton, 1981; Milner, 1963). It is assumed that an important processing component in this task is the ability to inhibit old rules when attempting to learn new rules for the categorization of multiattribute stimuli. Thus, larger performance decrements in this task for elderly than for young subjects would provide support for the frontal model of aging and inhibition.
A second task that we have included has been referred to as the stopping paradigm (Lappin \& Eriksen, 1966; Logan, in press; Welford, 1952). In this paradigm, subjects are asked to respond to a visual stimulus and abort their response in the unlikely event that they hear a tone (e.g., stop signals or tones occur on $25 \%$ of the trials). Thus, subjects are required to intentionally inhibit an overt response. The stopping task requires subjects to monitor for an auditory signal while responding to the visual stimulus, in essence a dual task.

Young adults perform the stopping task very well, inhibiting responses on demand in a variety of "go" tasks (for reviews see Logan, in press; Logan \& Cowan, 1984). The latency of the stopping response is very fast, on the order of $200 \mathrm{~ms}$, and largely independent of the go task. Children inhibit nearly as well as young adults, though their stopping responses have longer latencies (Schachar \& Logan, 1990). Hyperactive children cannot inhibit as well as normals and other psychiatric controls (Schachar \& Logan, 1990), though their stopping performance is improved by administering stimulant medication (Tannock, Schachar, Carr, Chajczyk, \& Logan, 1989).

Given the assumption that the stopping task includes dualtask components, monitoring for tones while responding to visual stimuli, as well as the requirement to rapidly shift response strategies, there is reasonable data to suggest that stopping performance should rely, in part, on frontal lobe processing. For example, Corbetta et al. (1991) has found evidence in PET studies for substantial activation of the anterior cingulate, a component of the frontal lobes, during dual-task performance. Similarly, Duncan (in press) has reported that patients with frontal lesions show substantial decrements in dual-task performance. Additional support for the assertion that performance in the stopping task is subserved, in part, by the frontal lobes is provided by research that has found an association between the ability to shift cognitive and response sets and frontal lobe function (Shallice \& Burgess, 1991). Thus, age-related deficits in performance in the stopping task and, in particular, in measures of subjects' ability to inhibit their overt responses would be supportive of the frontal model.

We also included the response compatibility paradigm, popularized by B. Eriksen and Eriksen (1974), in our battery. In this task, subjects are asked to respond to a target and ignore flanking distractors. RTs are slowed and accuracies are reduced when the distractors are incompatible with the response of the target. There is now fairly strong evidence that this performance effect can be attributed, in large part, to interference between the target and distractor responses (Coles et al., 1985; C. Eriksen, Coles, Morris, \& O'Hara, 1985). This task clearly requires the identification of the stimulus as well as its location and therefore logically necessitates the utilization of processing mechanisms in the dorsal (where) and ventral (what) visual pathways. Thus, the dorsal-ventral model would predict age-related differences in the magnitude of the response compatibility effect. Predictions concerning the role of the frontal lobes in the performance of this task are more equivocal. On the one hand, the fact that performance entails dealing with incompatible response tendencies similar to those in the stopping and WCST tasks suggests that task performance might be subserved, in part, by the frontal lobes. On the other hand, target identity and location are clearly indicated, and there is no requirement to 
switch from one response to another during the course of a response compatibility trial. These characteristics would appear to lend themselves to distractor filtering through the posterior attentional system (Posner, 1992), thereby possibly precluding the need for frontal lobe processing.

We also included a manipulation that involves spatial attention. In the negative priming task, we included a cuing manipulation, in which a location precue preceded the target by either 0,100 , or $200 \mathrm{~ms}$. Because the precuing operation appears to be subserved by the dorsal visual pathway (where system) both the dorsal-ventral and frontal models would predict a lack of agerelated differences in performance under these conditions.

Earlier we discussed the dissociation in age-related effects in the identity-based and location-based negative priming paradigms. In fact, this dissociation was the impetus for Connelly and Hasher's (1993) proposal that separate inhibitory mechanisms subserve the processing of location and identity information and that the latter mechanism is more susceptible to aging than the former mechanism. We examine this issue by including a negative priming paradigm that incorporates both identity and location components. Given that processing in these tasks presumably occurs, in part, in the visual pathways, the frontal model predicts that neither the identity nor location components should display age-related differences in performance.

Finally, we have included a self-report Cognitive Failures Questionnaire (CFQ; Broadbent, Cooper, FitzGerald, \& Parkes, 1982) in an effort to link laboratory tests of inhibitory function to everyday experiences that are associated with facile or inefficient inhibitory processing. In fact, an association between scores on the CFQ and negative priming effects has been previously reported. Tipper and Baylis (1987) found that the number of self-reported cognitive failures was inversely related to the magnitude of the negative priming effect. Thus, subjects who were good selectors as indicated by a substantial negative priming effect also reported fewer memory, attention, and motor failures than subjects who were poor selectors (e.g., subjects who produced a small negative priming effect). In the present study, we were interested in the differences between young and old adults on the CFQ questionnaire as well as the relationship between CFQ scores and other measures of inhibitory function.

\section{Method}

\section{Subjects}

Thirty-two young ( 12 men and 20 women) and 30 old ( 14 men and 16 women) adults participated in the study. The young subjects ranged in age from 18 to 28 years $(M$ age $=20.6$ ), whereas the old subjects ranged in age from 60 to 74 years $(M$ age $=67.8$ ). The subjects were paid $\$ 5$ per hour for their participation in the study.

All subjects were screened for use of any medication that would influence performance on the experimental tasks (e.g., psychotropic drugs, beta blockers, etc.) and for near and far visual acuity. All of the subjects possessed corrected visual acuities of at least 20/40. The mean corrected acuity of the young and old subjects was 20/21.3 and 20/23.0, respectively. These differences were not statistically significant.

The subjects were administered the Kaufman Brief Intelligence Test (Kaufman \& Kaufman, 1990) and the Digit Span subtest from the Wechsler Adult Intelligence Scale-Revised (WAIS-R; Wechsler, 1981). The mean standardized composite scores for the Kaufman Brief Intelligence Test were $117.8(S D=8.5)$ and $117.6(S D=8.4)$ for the young and old subjects, respectively. The mean standardized scores for the Vocabulary and Matrices scales were $116.2(S D=5.8)$ and $115.1(S D=$ $8.2)$, respectively, for the young and $116.5(S D=7.3)$ and $115.0(S D=$ 7.8 ), respectively, for the old subjects. The mean WAIS-R Forward Digit Span scores were 9.3 $(S D=2.3)$ and $8.6(S D=2.1)$ for the young and old group, respectively. The mean WAIS-R Backward Digit Span scores were $7.9(S D=2.9)$ and $7.7(S D=2.4)$ for the young and old group, respectively. In addition, $t$ tests failed to indicate any significant difference between the age groups on the scores obtained in the Kaufman Intelligence and Digit Span tests.

All of the young and old subjects were also asked to rate their health, relative to their age group, on a scale of 1 (excellent) to 4 (poor) and to indicate the number of years of formal education that they received. The groups did not differ on either of these factors. The mean health rating for the young and old groups was $1.53(S D=0.51)$ and $1.47(S D$ $=0.50$ ), respectively. The mean number of years of formal education for the young and the old groups was $16.4(S D=1.1)$ and $16.3(S D=$ 1.8 ), respectively.

\section{Apparatus}

The negative priming, response compatibility, stopping, and simple reaction time (SRT) tasks were performed on IBM AT computers with video graphics monitors and graphic cards. In all cases, the subjects responded with keys on the standard IBM AT keyboard. Subjects were seated alone in a small, comfortably lit room for each of the experimental sessions.

\section{Procedure}

The experiment was conducted in seven $11 / 2-\mathrm{hr}$ sessions within a period of 2 weeks. The first session was devoted to the collection of data on demographics, lifestyle, and health status. The subjects were also administered the WAIS-R Digit Span subtest, Kaufman Brief Intelligence Test, near and far visual acuity tests, WCST, and the CFQ during the first session. Sessions 2 through 6 were devoted to the computerbased testing protocols.

Essentially two different paradigms, with several subcomponents each, were run in the five experimental sessions. These paradigms included stopping and negative priming. The stopping paradigm was conducted in four sessions, whereas the negative priming paradigm was conducted over two sessions. The order of presentation of these two paradigms was counterbalanced across subjects. The details concerning these paradigms, and their subcomponents, are delineated in the descriptions of each task provided below.

\section{Experimental Paradigms}

WCST. The WCST was administered in the standard fashion (Berg, 1948; Heaton, 1981) with 128 cards. The task requires subjects to discover a rule according to which the cards are to be sorted. Cards are matched on one of three possible characteristics of the symbol on the card: color, shape, or numerosity. At the start of the test, four different stimulus cards are put in front of the subject (one red triangle, two green stars, three yellow crosses, and four blue circles). The subject is then told to place each of the response cards in front of a stimulus card. The subject is not informed of the correct sorting rule but is told whether each response is right or wrong. Following 10 consecutive correct sorts, the initial sorting rule is changed without warning. This procedure continues until the completion of six categories or the sorting of the 128 cards.

The following six standard dependent measures (see Heaton, 1981, for a detailed description of the scoring of these measures) were computed for each of the subjects: total errors, perseverative responses, per- 
Table 1

Cognitive Failures Questions With Mean Scores for Young and Old Subjects

\begin{tabular}{|c|c|c|c|c|c|}
\hline \multirow[b]{3}{*}{ Questions } & \multicolumn{4}{|c|}{ Age group } & \multirow[b]{3}{*}{$t$ test } \\
\hline & \multicolumn{2}{|c|}{ Young } & \multicolumn{2}{|c|}{ Old } & \\
\hline & $M$ & $S D$ & $M$ & $S D$ & \\
\hline $\begin{array}{l}\text { 1. Do you read something and find you haven't been } \\
\text { thinking about it and must read it again? }\end{array}$ & 63.3 & 21.0 & 53.3 & 17.1 & 2.05 \\
\hline 2. Do you find you forgot why you went from one & & & & & \\
\hline part of the house to the other? & 35.2 & 17.8 & 46.3 & 21.0 & -2.25 \\
\hline 3. Do you fail to notice sign posts on the road? & 32.8 & 14.8 & 32.7 & 16.6 & 0.01 \\
\hline 4. Do you find you confuse left and right when & & & & & \\
\hline giving directions? & 20.3 & 22.4 & 23.8 & 17.5 & -0.68 \\
\hline 5. Do you bump into people? & 24.2 & 18.3 & 20.0 & 15.3 & 0.97 \\
\hline $\begin{array}{l}\text { 6. Do you find that you forget that you've turned off } \\
\text { a light or the stove or locked the door? }\end{array}$ & 29.7 & 21.5 & 36.6 & 18.3 & -1.37 \\
\hline $\begin{array}{l}\text { 7. Do you fail to listen to people's names when you } \\
\text { are meeting them? }\end{array}$ & 60.2 & 23.6 & 59.6 & 25.4 & 0.09 \\
\hline $\begin{array}{l}\text { 8. Do you say something and realize afterwards that } \\
\text { it might be taken as insulting? }\end{array}$ & 38.3 & 17.9 & 37.1 & 15.6 & 0.28 \\
\hline $\begin{array}{l}\text { 9. Do you fail to hear people speaking to you when } \\
\text { you are doing something else? }\end{array}$ & 44.5 & 20.8 & 45.4 & 21.5 & -0.16 \\
\hline 10. Do you lose your temper and regret it? & 33.5 & 20.6 & 36.2 & 14.7 & -0.56 \\
\hline $\begin{array}{l}\text { 11. Do you leave important letters unanswered for } \\
\text { days? }\end{array}$ & 31.3 & 28.2 & 30.8 & 19.7 & 0.07 \\
\hline $\begin{array}{l}\text { 12. Do you find you forget which way to turn on a } \\
\text { road you know well but rarely use? }\end{array}$ & 20.3 & 16.1 & 20.0 & 16.6 & 0.08 \\
\hline $\begin{array}{l}\text { 13. Do you fail to see what you want in a supermarket } \\
\text { (although it's there)? }\end{array}$ & 32.8 & 13.8 & 38.8 & 24.9 & -1.64 \\
\hline $\begin{array}{l}\text { 14. Do you find yourself suddenly wondering whether } \\
\text { you've used a word correctly? }\end{array}$ & 29.7 & 21.4 & 41.7 & 18.9 & -2.33 \\
\hline 15. Do you have trouble making up your mind? & 47.7 & 20.4 & 41.4 & 22.4 & 1.13 \\
\hline 16. Do you find you forget appointments? & 25.3 & 14.8 & 21.4 & 16.3 & 1.07 \\
\hline $\begin{array}{l}\text { 17. Do you forget where you put something like a } \\
\text { newspaper or book? }\end{array}$ & 37.1 & 15.7 & 41.4 & 18.0 & -0.98 \\
\hline $\begin{array}{l}\text { 18. Do you find you accidentally throw away the } \\
\text { thing you want and keep what you meant to } \\
\text { throw away-as in the example of throwing away } \\
\text { the matchbook and putting the used match in } \\
\text { your pocket? }\end{array}$ & 20.3 & 18.4 & 18.3 & 14.5 & 0.47 \\
\hline 19. Do you daydream when you ought to be listening & & & & & \\
\hline to something? & 54.9 & 25.3 & 36.7 & 17.0 & $3.30^{*}$ \\
\hline 20. Do you find you forget people's names? & 58.5 & 28.0 & 72.6 & 22.7 & -2.09 \\
\hline $\begin{array}{l}\text { 21. Do you start doing one thing at home and get } \\
\text { distracted into doing something else } \\
\text { (unintentionally)? }\end{array}$ & 453 & 20.5 & 525 & 22.2 & 5 \\
\hline 22. Do you find you can't quite remember something & 45.3 & 20.5 & J2.J & 22.2 & 1.50 \\
\hline although it"s on "the tip of your tongue"? & 50.0 & 12.7 & 62.5 & 17.1 & $-3.29 *$ \\
\hline $\begin{array}{l}\text { 23. Do you find you forget what you came to the } \\
\text { shops to buy? }\end{array}$ & 21.9 & 18.8 & 28.3 & 19.4 & -1.33 \\
\hline 24. Do you drop things? & 30.5 & 16.5 & 28.3 & 15.7 & 0.52 \\
\hline 25. Do you find you can't think of anything to say? & 36.7 & 20.0 & 26.5 & 19.6 & 1.99 \\
\hline
\end{tabular}

Note. Questions from "The Cognitive Failures Questionnaire (CPQ) and its correlates," by D. E. Broadbent, P. F. Cooper, P. Fitzgerald, and K. R. Parker, 1982, British Journal of Clinical Psychology, 21, 1-16. Copyright 1982 by the British Psychological Society. Reprinted with permission.

* Significant at $p<.01$.

severative errors, nonperseverative errors, number of categories completed, and trials to complete the first category.

$C F Q$. Twenty-five questions were administered to the subjects (Broadbent et al., 1982). A list of the questions is provided in Table 1. Subjects rated the questions on a 5-point scale with $0=$ never, $1=$ very rarely, $2=$ occasionally, $3=$ quite often, and $4=$ very often. For purposes of data analysis, the scores were rescaled to 0 to 100 such that $0=$ never and $100=$ very often. The CFQ has been found to be reliable with test- retest correlations above .80 for up to periods of 65 weeks (Broadbent et al., 1982).

Negative priming. Subjects performed the negative priming task in

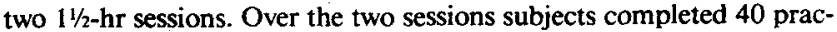
tice and 2,264 experimental couplets, with each couplet consisting of a prime-probe display. The subjects' task was to respond to a cued target in a display of four letters. The target was indicated by an underline and was either a capital $D, V, M$, or $L$. One target and three identical 
distractors appeared in each display. Subjects responded to the target with the appropriate letter key on the computer keyboard. Thus, when a $D$ served as the target subjects pressed the $D$ key, when a $V$ was the target they pressed the $V$ key, and so on. Subjects were instructed to respond both quickly and accurately.

An individual couplet consisted of the following sequence of events. A couplet was initiated by pressing the space bar. A fixation cross appeared in the center of the screen $100 \mathrm{~ms}$ after the space bar was pressed. The fixation cross remained on the screen throughout the prime-probe couplet. Four letters appeared on the screen $400 \mathrm{~ms}$ after the fixation cross appeared. This display, hereinafter referred to as the prime display, remained on the screen for $200 \mathrm{~ms}$. One of the letters in the prime display was the target that was indicated by an underline that appeared either 200,100 , or $0 \mathrm{~ms}$ before the letters (e.g., $-200,-100$, or $0 \mathrm{~ms}$ stimulus onset asynchrony [SOA]). Four hundred milliseconds following the response to the prime display (or $1,500 \mathrm{~ms}$ from prime display onset if there was no response) a second display of four letters, with one underlined target and three identical distractors, appeared for $200 \mathrm{~ms}$. Hereinafter this display is referred to as the probe display. Subjects were given a maximum of $1,500 \mathrm{~ms}$ to respond to the target in the probe display. Accuracy feedback for the couplet followed the response to the probe display.

Each of the four letters appeared equally often as a target and distractor across couplets. The target also occurred equally often in each of the four positions, at the 12:00, 3:00,6:00, and 9:00 positions around an imaginary circle, across couplets. Finally, the relationship between target position in the prime and probe displays (e.g., within each couplet of prime and probe displays) was counterbalanced across couplets. In other words, the target position was equivalent $25 \%$ of the time in the prime and the probe displays of a couplet.

The prime and probe displays were equivalent in terms of the size and positioning of the fixation cross and letters. Subjects viewed the displays from a distance of $60 \mathrm{~cm}$. At this distance, the diameter of the imaginary circle on which the letters appeared was $1.90^{\circ}$ of visual angle. Each of the four letters subtended a visual angle of $0.382^{\circ}$ vertically by $0.334^{\circ}$ horizontally. The edge-to-edge separation between letters was $1.05^{\circ}$ horizontally and $1.15^{\circ}$ vertically. The underline subtended $0.382^{\circ}$ of visual angle, appearing $0.19^{\circ}$ below the cued letter. Finally, the fixation cross appeared in the center of the display and subtended $0.382^{\circ}$ both horizontally and vertically.

Three different prime-probe conditions were presented in the practice and experimental couplets. The three conditions are illustrated in Figure 1. In the Control 1 condition, the target and three distractors were all the same in the prime display. Furthermore, the letters presented in the prime display differed from those presented in the subsequent probe display. In the Control 2 condition, the target differed in identity from the three distractors in the prime display. The prime letters, in turn, differed from those presented in the probe display. Finally, in the IR condition, the target differed in identity from the three distractors as in the Control 2 condition prime display. However, in the IR probe display, the target was the same as the distractors from the prime display. In this case, the three distractors were letters that had not appeared in the previous prime display.

Several varieties of inhibition could be examined by contrasting performance in different subsets of these three conditions. First, a comparison between the Control 1 and Control 2 prime displays enabled us to assess performance costs attributable to response incompatible distractors. Second, a comparison between the Control 2 and IR probe displays enabled us to assess the magnitude of the negative priming effect. $\mathrm{Fi}^{-}$ nally, the manipulation of cue SOA in the prime displays enabled us to assess the degree to which subjects could reduce distractor interference by prefocusing their attention on the target location.

Stopping. Subjects performed the stopping paradigm in four $11 / 2-\mathrm{hr}$

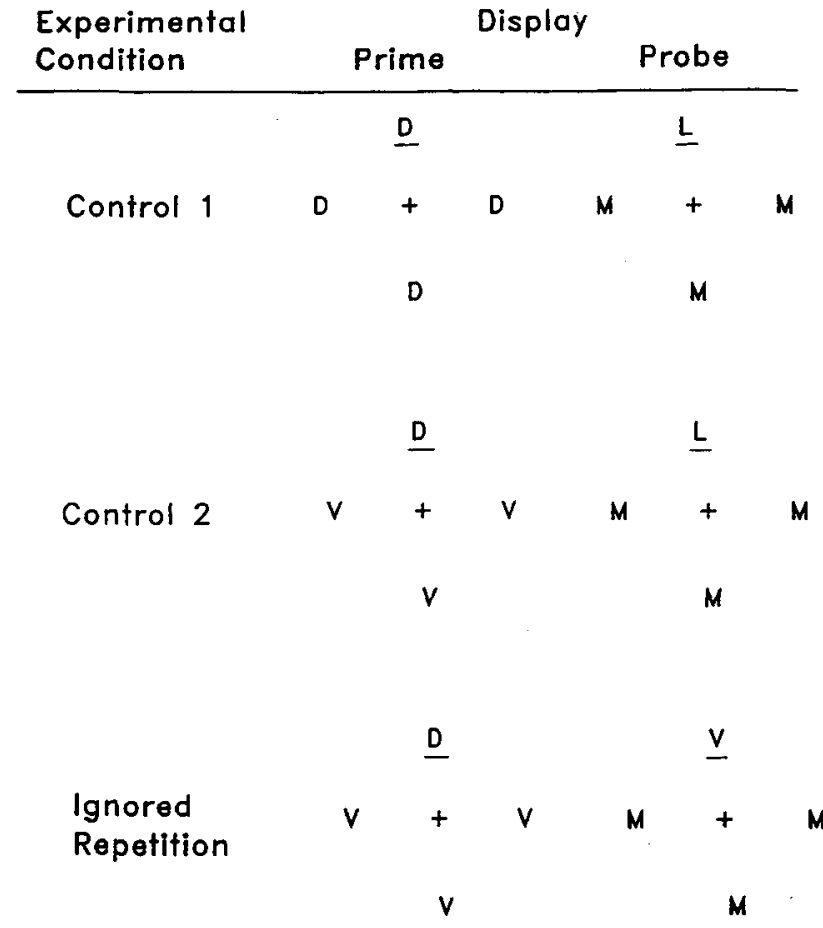

Figure 1. A graphic illustration of the three different conditions in the negative priming paradigm. The underlined letter is the target; the other letters are distractors.

sessions. The stopping paradigm consisted of several interrelated component tasks.

In the first session, subjects performed the response compatibility (B. Eriksen \& Eriksen, 1974) component of the stopping paradigm. In this task, subjects were instructed to respond to the central letter of a threeletter array. The target letter always appeared at the same location in the center of the display and was either an $X, Y, S$, or $C$. Subjects pressed one response key if an $X$ or a $Y$ appeared in the target position and pressed another response key if an $S$ or a $C$ appeared in the center of the display. Response keys were the $A$ and $L$ on the standard IBM AT keyboard. The mapping of response keys to targets was counterbalanced across subjects.

Three different conditions were included in this task. In the compatible response condition, the target letter was surrounded by two distractors with the same response (e.g., an $X$ surrounded by $Y$ s or an $S$ surrounded by $C \mathrm{~s}$ ). In the incompatible response condition, the target letter was surrounded by two letters with the other response (e.g., a $Y$ surrounded by $C s$ or $S \mathrm{~s}$ or an $S$ surrounded by $X \mathrm{~s}$ or $Y \mathrm{~s}$ ). Finally, in the neutral condition, one of the four target letters was surrounded by two letters that were never responded to as a target (e.g., an $H$ or a 7 ). Each of the three conditions occurred one-third of the time.

The timing of each of these trials was as follows. Each trial was initiated by pressing the spacebar. After a $500-\mathrm{ms}$ delay, a fixation cross appeared in the center of the display for $500 \mathrm{~ms}$. The fixation cross was followed by a $300-\mathrm{ms}$ blank interval, and then the stimulus array was presented for $500 \mathrm{~ms}$. Subjects had $1,500 \mathrm{~ms}$ to respond following the onset of the three-letter display. Seven blocks of 144 trials were performed in Session 1. RT and accuracy feedback were provided at the end of each block of trials. Subjects were instructed to respond both quickly and accurately.

Subjects viewed the display at a distance of $60 \mathrm{~cm}$. Each of the letters subtended a visual angle of $0.477^{\circ}$ horizontally and $0.573^{\circ}$ vertically. 
The edge-to-edge separation between the letters was $0.10^{\circ}$ of visual angle. The fixation cross, which occupied the same position at the target letter, was $0.382^{\circ}$ by $0.382^{\circ}$.

The subjects also performed an SRT task in the first session. The subjects were instructed to respond to the presentation of a $1,000 \mathrm{~Hz}, 65$ $\mathrm{dB}$ tone ( $100 \mathrm{~ms}$ duration). The trials were self-paced and were initiated with the spacebar. Once initiated, there was a $500-\mathrm{ms}$ delay before the presentation of a fixation cross for $500 \mathrm{~ms}$. The onset of the tone occurred at 1 of 12 delays following the offset of the fixation cross. These delays were derived from each subject's RT distribution in the response compatibility task such that the 20 th, 40 th, 60 th, and 80 th percentiles of the distribution for the three response compatibility conditions (e.g., compatible, incompatible, and neutral) were selected as the 12 delays. Each subject performed 144 SRT trials, 72 with the index finger of each hand. The RTs from this task were used to adjust the timing of the stop signal in the stopping task.

Subjects performed the stopping task in Sessions 2 through 4 . This task was identical to the response compatibility task with the exception of the addition of an occasional stop signal. The subjects were instructed to perform the task as they had in the response compatibility session. However, whenever a tone occurred, they were to inhibit their response to the target.

The timing of each trial in the stopping task was identical to that described for the response compatibility task, with the exception of the presentation of a $1,000 \mathrm{~Hz}, 65 \mathrm{~dB}$ tone, which occurred on $25 \%$ of the trials. The times at which this tone occurred, hereinafter referred to as the stop-signal delay, were calculated separately for each of the subjects on the basis of their RT distribution in the response compatibility task and their SRT.

Current models of the stop-signal paradigm assume that performance depends on a race between the go process and the stop process. If the go process finishes first, the response is executed; if the stop process finishes first, the response is inhibited (Logan \& Cowan, 1984; Osman, Kornblum, \& Meyer, 1986). The probability of responding given a stop signal depends on the relative finishing times of the stop and go processes. The delay between the stop signal and the go signal is important in determining relative finishing time. The shorter the delay, the greater the likelihood that the stop process will finish first.

The finishing time of the stop process is approximately the sum of the stop-signal delay and the stop-signal RT. ${ }^{1}$ The probability of responding given a stop signal depends on where this sum intersects the go-signal RT distribution. The probability of responding equals the proportion of the go-signal RT distribution that is less than or equal to the sum.

We wanted to present stop signals so that subjects would inhibit specified proportions of their responses (i.e., $20 \%, 40 \%, 60 \%$, and $80 \%$ ), so we arranged the stop-signal delays such that the sum of the stop-signal delay plus the stop-signal RT would intersect the go-signal distribution at the 20 th, 40 th, 60 th, and 80 th percentiles. We used SRT to the stopping tone as an estimate of stop-signal RT because previous research has shown that SRT and stop-signal RT are approximately equal.

Twelve separate stop-signal delays were calculated for each subject. The stop-signal delays were calculated by subtracting the SRT from the RTs at the 20th, 40th, 60th, and 80 th percentiles of the RT. distributions of the compatible response, incompatible response, and neutral conditions of the response compatibility task. The stop-signal delays were updated each session using the no-stop-signal RTs (e.g., the RTs from the $75 \%$ of the trials in which a stop signal did not occur) from the previous session.

Subjects performed seven blocks of 144 trials in each of the three stop-signal sessions. These trials were equally divided across the three conditions in the response compatibility task: the compatible response, incompatible response, and neutral condition. Twenty-five percent of the trials in each session were stop-signal trials (e.g., 252 trials per session), $75 \%$ of the trials were no-stop-signal trials.
Table 2

Wisconsin Card Sorting Test Means for Young and Old Subjects

\begin{tabular}{|c|c|c|c|c|c|}
\hline \multirow[b]{3}{*}{ Measures } & \multicolumn{4}{|c|}{ Age group } & \multirow[b]{3}{*}{$i$ test } \\
\hline & \multicolumn{2}{|c|}{ Young } & \multicolumn{2}{|c|}{ Old } & \\
\hline & $M$ & $S D$ & $M$ & $S D$ & \\
\hline Categories & 5.9 & 0.53 & 4.2 & 2.1 & $4.07^{*}$ \\
\hline Total errors & 14.8 & 11.2 & 36.7 & 26.4 & $-4.20^{*}$ \\
\hline \multicolumn{6}{|l|}{ Perseverative } \\
\hline responses & 11.1 & 7.9 & 26.5 & 24.1 & $-3.40^{*}$ \\
\hline Perseverative errors & 8.3 & 6.1 & 20.0 & 18.9 & $-3.29^{*}$ \\
\hline Trials to first category & 12.2 & 3.9 & 14.6 & 8.1 & -1.41 \\
\hline \multicolumn{6}{|l|}{ Concept level } \\
\hline responses & 63.4 & 7.0 & 57.2 & 21.9 & 1.49 \\
\hline
\end{tabular}

* Significant at $p<.01$.

Several varieties of inhibition could be examined in the stopping paradigm. First, the use of incompatible, compatible, and neutral distractors in the response compatibility task (e.g., no-stop-signal trials) enabled us to examine both the facilitatory (neutral minus compatible) and inhibitory (incompatible minus neutral) effects of the distractors on the processing of the target letter. Second, the introduction of the stop signal enabled us to assess the degree to which the young and old subjects could inhibit an overt response across several different (compatible, incompatible, and neutral) experimental conditions. The speed of inhibition was also estimated from the data.

\section{Results and Discussion}

This section is organized in the following manner. First, we discuss each of the tests separately, focusing on the relationship between inhibitory function and age. Second, we examine the relations among different varieties of inhibitory function in an effort to determine the generality of decline in inhibitory function during aging.

\section{WCST}

The grand mean scores for the six dependent variables for both the young and elderly subjects are presented in Table 2 . We performed $t$ tests to determine whether there were significant differences between the young and elderly groups. As can be seen from the table, young subjects completed more categories and made fewer perseverative and nonperseverative errors than the old subjects. Thus, consistent with our hypothesis, old subjects had more difficulty altering their responses on the basis of changing patterns of experimenter feedback.

Interestingly, however, both the young and the old subjects

\footnotetext{
${ }^{1}$ This analysis and the procedure for estimating stop-signal RT assume that the stop-signal RT is a constant. This assumption is unlikely to be valid, but several analyses have shown that its validity has little effect on the validity of the estimates of stop-signal RT (De Jong, Coles, Logan, \& Gratton, 1990; Logan \& Cowan, 1984). Estimation procedures that do not assume constant stop-signal RT produce comparable estimates and usually require many more observations (Logan, in press).
} 
took an equivalent number of trials to complete the first category and obtained similar scores on the concept level response measure. These two variables are measures of conceptual ability (Heaton, 1981). The former provides a measure of the conceptualization of the first category, whereas the latter provides an overall measure of the degree to which subjects make responses based on the hypothesized category. Thus, it would appear that whereas the old subjects had a difficult time switching among categories, their conceptual ability was unimpaired.

Our data are interesting with respect to previous studies that have examined the relationship between age and performance on the WCST. Although all of these studies have found a decrease in performance on the WCST, particularly on measures of the number of categories achieved and number of perseverative errors (Arbuckle \& Gold, 1993; Berg, 1948; Heaton, 1981; Loranger \& Misiak, 1960), some studies have found that these performance decrements are not apparent until subjects are in their 80s (Haaland et al., 1987). Haaland et al. attributed the high level of performance attained on the WCST by their elderly subjects to their good health. Previous studies had included nursing-home patients in their samples and had failed to provide explicit indications of subject health and mental status.

However, our elderly subjects, who ranged in age from 60 to 74 years, were clearly high functioning, possessing a mean IQ of a standard deviation above the mean as well as a mean of 16.3 years of education. Our subjects were also in good physical health and were not taking any medications that would be detrimental to their performance. Despite their good health and high level of mental functioning, the elderly subjects performed more poorly than the young subjects on aspects of the task that required switching categories on the basis of experimenter feedback. Thus, although the relationship between age and WCST performance deserves further study, the bulk of the empirical evidence suggests a decline in performance with age, even with healthy, high-functioning subjects.

\section{$C F Q$}

Two different sets of analyses were performed on the data obtained from the CFQ. First, we performed a $t$ test on the mean composite scores across the 25 questions. Second, we compared the young and old groups on each of the 25 questions. ${ }^{2}$ Given the large number of $t$ tests performed on this data we set alpha at .01 .

The composite scores did not differ between the young and old groups $(p<.60)$. The estimated power for this comparison was $.62 .^{3}$ The mean composite scores for the young and old groups were 37.0 and 37.9 , respectively. Thus, at least at a general level, the old subjects did not indicate a larger number of cognitive failures than the young subjects.

Table 1 presents each of the 25 questions along with the group means and $t$ tests. As can be seen from the table, there were only two questions on which the young and old adults differed. The old subjects reported having significantly more difficulty than the young subjects retrieving familiar information. This could be construed as a failure of declarative memory ( $\mathrm{N}$. Cohen \& Eichenbaum, 1992). It is interesting to note, however, that there were also a number of questions that concerned memory-based cognitive failures (e.g., Questions 6, 12, 16, 17, and 23) on
Table 3

Mean Correct Reaction Times (RTs; in milliseconds) and Error Rates for the Response Compatibility Trials in Session I of the Stopping Task

\begin{tabular}{|c|c|c|c|c|c|c|}
\hline \multirow[b]{3}{*}{ Age group } & \multicolumn{6}{|c|}{ Response compatibility condition } \\
\hline & \multicolumn{2}{|c|}{ Compatible } & \multicolumn{2}{|c|}{ Neutral } & \multicolumn{2}{|c|}{ Incompatible } \\
\hline & $M$ & $S D$ & $M$ & $S D$ & $M$ & $S D$ \\
\hline \multicolumn{7}{|l|}{ Young } \\
\hline RT & 451 & 73 & 462 & 69 & 480 & 74 \\
\hline Error rate & 2.9 & 1.9 & 3.8 & 2.1 & 7.4 & 3.8 \\
\hline \multicolumn{7}{|l|}{ Old } \\
\hline RT & 562 & 78 & 570 & 79 & 589 & 87 \\
\hline Error rate & 2.0 & 2.0 & 3.0 & 2.4 & 6.3 & 4.6 \\
\hline
\end{tabular}

which young and old subjects did not differ in their ratings. The young subjects reported more daydreams or task-unrelated thoughts than did the old adults. This result is consistent with Giambra's (1989) finding that young subjects report more irrelevant thought intrusions than old subjects. In general, our results are consistent with reports by Rabbitt (1990) and Kane et al. (1994) that old subjects do not report more cognitive failures in everyday activities than do young subjects.

\section{Stopping Task}

We examine two different issues within the stopping task. First, an analysis of the response compatibility data enables us to assess the influence of the response compatible and incompatible distractors on the processing of the target stimulus. Two analyses are performed on this data. One analysis is conducted on the data acquired in the practice session. There were no stop signals presented in this session. A second analysis is conducted on the data collected in Sessions 2, 3, and 4. These data were collected on the $75 \%$ of the trials on which a stop signal did not occur. The second issue addressed by the data collected in the stopping task is the degree to which the young and old subjects were able to stop an overt response. The data analyzed to address this issue include stop-signal RTs and the probability of responding given a stop signal, $P$ (respond $\mid$ signal).

Response compatibility analyses. The data collected in the practice session are displayed in Table 3. These data were analyzed in a two-factor analysis of variance (ANOVA) with Age as

\footnotetext{
${ }^{2}$ There were two reasons why we did not perform a factor analysis on the questionnaire data in an effort to examine the differences in young and old subjects' responses. First, Broadbent et al. (1982) reported a positive correlation among all of the questions, thereby indicating the possibility of a common cognitive failures component. Furthermore, Broadbent et al. carried out factor analyses on a variety of different data sets, and other than obtaining a general factor, they failed to obtain any additional stable factors across the data sets. Second, given the number of variables in the CFQ, we did not possess a sufficient number of observations (subjects) to ensure a stable factor solution.

${ }^{3}$ Power analyses were computed assuming a moderate-sized youngold difference ( $1 / 2$ standard deviation), a one-tailed alpha value at .05 , and a group sample size of 31 (J. Cohen, 1988).
} 
the between-subjects factor and Response Compatibility Condition as a within-subjects factor. Both of the main effects were significant. Older subjects were slower than young subjects, $F(1$, $60)=31.6, M S_{\mathrm{e}}=17,577, p<.01$. RTs increased from the compatible to the neutral to the incompatible trials, $F(2,120)$ $=98.5, M S_{\mathrm{e}}=15.257, p<.01 .^{4}$ The Age $\times$ Response Compatibility interaction did not attain statistical significance $(p>$ .75). The estimated power for the incompatible-compatible age group comparison was .62. The differences between the neutral and compatible conditions were 11 and $8 \mathrm{~ms}$ for the young and old subjects, respectively. The differences between the neutral and incompatible conditions were 18 and $19 \mathrm{~ms}$ for the young and old subjects, respectively. Both of these differences (e.g., neutral minus compatible or incompatible minus neutral) provide a measure of the influence of distractor processing on target processing. The neutral minus compatible difference is usually considered to be an index of processing benefits, whereas the incompatible minus neutral difference is considered to be a measure of processing costs.

An ANOVA with the same structure was performed on the error rate data. The Response Compatibility factor attained statistical significance, $F(2,120)=68.3, M S_{\mathrm{e}}=0.0004, p<.01$. The compatible trials were more accurate than the neutral trials, which were more accurate than the response incompatible trials.

A second set of analyses was performed on the $75 \%$ of the trials on which a stop signal did not occur. The mean RT and error rate data for the old and young subjects in the second through fourth sessions are presented in Table 4 . The RT data were quantified in a three-way ANOVA with Age as a betweensubjects factor and Response Compatibility Condition and Session as within-subjects factors. Significant main effects were obtained for Age, $F(1,60)=30.5, M S_{\mathrm{e}}=100,492, p<.01$; Session, $F(2,120)=19.7, M S_{e}=3,145, p<.01$; and Response Compatibility factors, $F(2,120)=168.7, M S_{\mathrm{e}}=185, p<.01$. Older subjects performed more slowly than young subjects. RTs decreased with increased practice across sessions. RTs were fastest for the response compatible trials, intermediate for the neutral trials, and slowest for the response incompatible trials. Consistent with the practice trials, the Age $\times$ Response Compatibility interaction did not attain statistical significance $(p>$ $.65)$. The estimated power for the incompatible-compatible age group comparison was .62 .

Interestingly, the differences between the three response compatibility conditions did not vary with practice. The processing benefits (e.g., neutral minus compatible) were 7, 9, and $10 \mathrm{~ms}$ for the young and 12,11, and $7 \mathrm{~ms}$ for the old in Sessions 2, 3, and 4 . The processing costs (e.g., incompatible minus neutral) were 17,15 , and $15 \mathrm{~ms}$ for the young and 18,19 , and $19 \mathrm{~ms}$ for the old in Sessions 2, 3, and 4. None of the other two- or threeway interactions attained statistical significance.

A second ANOVA with the same factor structure was performed on the error rate data. Significant effects included Age, $F(1,60)=15.9, M S_{\mathrm{e}}=0.0068, p<.01$, and Response Compatibility, $F(2,120)=131.9, M S_{\mathrm{e}}=0.0013, p<.01$. Older subjects were more accurate than young subjects. Errors increased from the compatible to the neutral to the incompatible conditions. None of the other two- or three-way interactions were significant.
Table 4

Mean Correct Reaction Times (RTs; in milliseconds) and Error Rates for the Response Compatibility Trials in Sessions 2,3, and 4 of the Stopping Task

\begin{tabular}{|c|c|c|c|c|c|c|}
\hline \multirow{3}{*}{$\begin{array}{l}\text { Age group and } \\
\text { session }\end{array}$} & \multicolumn{6}{|c|}{ Response compatibility condition } \\
\hline & \multicolumn{2}{|c|}{ Compatible } & \multicolumn{2}{|c|}{ Neutral } & \multicolumn{2}{|c|}{ Incompatible } \\
\hline & $M$ & $S D$ & $M$ & $S D$ & $M$ & $S D$ \\
\hline \multicolumn{7}{|l|}{ Young } \\
\hline \multicolumn{7}{|l|}{ Session 2} \\
\hline RT & 416 & 73 & 423 & 73 & 440 & 75 \\
\hline Error rate & 2.9 & 2.0 & 5.0 & 2.6 & 10.2 & 5.3 \\
\hline \multicolumn{7}{|l|}{ Session 3} \\
\hline RT & 394 & 73 & 403 & 74 & 418 & 75 \\
\hline Error rate & 3.2 & 2.2 & 5.3 & 2.9 & 10.8 & 6.0 \\
\hline \multicolumn{7}{|l|}{ Session 4} \\
\hline RT & 389 & 66 & 398 & 65 & 413 & 68 \\
\hline Error rate & 3.0 & 2.0 & 6.0 & 3.2 & 10.9 & 5.1 \\
\hline \multicolumn{7}{|l|}{ Old } \\
\hline \multicolumn{7}{|l|}{ Session 2} \\
\hline RT & 569 & 91 & 581 & 93 & 599 & 99 \\
\hline Error rate & 1.5 & 1.1 & 2.9 & 2.5 & 5.9 & 4.8 \\
\hline \multicolumn{7}{|l|}{ Session 3} \\
\hline RT & 542 & 104 & 551 & 99 & 570 & 119 \\
\hline Error rate & 1.4 & 1.4 & 3.1 & 2.2 & 5.8 & 4.1 \\
\hline \multicolumn{7}{|l|}{ Session 4} \\
\hline RT & 527 & 86 & 534 & 83 & 553 & 96 \\
\hline Error rate & 1.6 & 1.5 & 2.8 & 2.3 & 6.0 & 4.7 \\
\hline
\end{tabular}

Note. These means were obtained from $75 \%$ of the trials on which a stop signal did not occur.

In summary, the expected effects of response compatibility were obtained in both the practice and no-stop-signal trials. More important, however, the old and young subjects showed equivalent response compatibility effects. Such a result would appear inconsistent with the claim that old subjects are more affected by distraction than young subjects (Layton, 1975; Rabbitt, 1965), at least in situations in which the target and distractor locations are predictable and stationary over trials.

Previous investigations of age-related differences in the response compatibility effect have produced mixed results. Wright and Elias (1979) found significantly smaller response compatibility effects for old than for young subjects. However, Farkas and Hoyer (1980) found that old subjects' performance was more severely disrupted than young subjects' when they responded to a target in the presence of similarly shaped distractors (see also R. Shaw, 1991). Cerella (1985a) hypothesized that these discrepant findings might be the result of uncontrolled age-related acuity differences rather than attentional factors. Thus, peripheral distractors would be expected to produce less interference, as in the Wright and Elias (1979) study, if old subjects possessed poorer peripheral acuity than young subjects. Consistent with his hypothesis, Cerella found that old subjects displayed a larger response compatibility effect than young

\footnotetext{
${ }^{4}$ Bonferroni $t$ tests were conducted to contrast compatibie and neutral and incompatible and neutral conditions. Both of these contrasts were significant at $p<.01$. All other contrasts reported in this article are performed with the Bonferroni $t$ test.
} 
Table 5

Mean Probability of Responding Given a Stop Signal,

$P($ Respond|Signal), for Each of the Stop-Signal

Delays and the Three Response Compatibility

Conditions for the Young and Old Subjects

\begin{tabular}{|c|c|c|c|c|c|c|c|}
\hline \multirow{3}{*}{$\begin{array}{l}\text { Age } \\
\text { group }\end{array}$} & \multirow{3}{*}{$\begin{array}{l}\text { Tone } \\
\text { delay }\end{array}$} & \multicolumn{6}{|c|}{ Response compatibility condition } \\
\hline & & \multicolumn{2}{|c|}{ Compatible } & \multicolumn{2}{|c|}{ Neutral } & \multicolumn{2}{|c|}{ Incompatible } \\
\hline & & $M$ & $S D$ & $M$ & $S D$ & $M$ & $S D$ \\
\hline \multirow{4}{*}{ Young } & .20 & .456 & .30 & .453 & .31 & .468 & .30 \\
\hline & .40 & .537 & .28 & .534 & .30 & .542 & .29 \\
\hline & .60 & .637 & .25 & .650 & .28 & .674 & .25 \\
\hline & .80 & .775 & .18 & .762 & .20 & .798 & .18 \\
\hline \multirow[t]{4}{*}{ Old } & .20 & .446 & .32 & .432 & .32 & .435 & .31 \\
\hline & .40 & .494 & .30 & .490 & .31 & .514 & .30 \\
\hline & .60 & .583 & .28 & .591 & .29 & .594 & .29 \\
\hline & .80 & .693 & .29 & .711 & .25 & .737 & .26 \\
\hline
\end{tabular}

Note. The data are collapsed across sessions.

subjects when distractors were close to the fovea (e.g., $0.7^{\circ}$ from fixation). However, this pattern of results reversed, with young subjects displaying a larger response compatibility effect, when the eccentricity of the distractors was increased (e.g., $3.8^{\circ}$ from fixation).

Given Cerella's (1985a) findings and the fact that our distractors were presented in fovea (e.g., $0.58^{\circ}$ from fixation), we might have expected that our old subjects would display a larger response compatibility effect than would the young subjects. However, the size of the response compatibility effect was equivalent for young and old subjects. Why might this be the case? One possibility that can be quickly discounted concerns the relative acuity of young and old subjects. If the old subjects had poorer acuity than the young subjects, we would expect less interference from the distractors for the old than for the young subjects. However, both the old and young subjects possessed equivalent levels of acuity. In fact, it appears that our subjects possessed better acuity than the old subjects tested by Cerella (e.g., 20/23 in the present study vs. at least 20/40 in Cerella's study). Two more likely possibilities include the fact that the old subjects in our study were (a) extremely high functioning and (b) well practiced in the task. In any event, our results, as well as the results obtained with the response compatibility component of the negative priming task (see below), suggest that increased susceptibility to distracting information is not an inevitable consequence of aging.

Stopping analyses. Two dependent variables were obtained from the stopping task in Sessions 2, 3, and 4. One variable was the probability of responding given a stop signal, $P$ (respond signal), and the second variable was the stop-signal RT. $P($ respond | signal) provides a measure of subjects' ability to inhibit an overt response. It reflects a race between the stop process and the go process, representing those cases in which the go process is faster than the stopping process. $P$ (respond/signal) should increase as stop-signal delay increases because the stopping process starts later at the longer delays and so is less likely to win the race.

Stop-signal RT was estimated from the data using the race model (Logan \& Cowan, 1984). According to the model, subjects will respond to the go signal if the go-signal response is faster than the stopping response. $P$ (respond / signal) represents the proportion of go-signal responses that are faster than the stopping response. The point in time at which the stopping process is finished can be estimated from the percentile on the gosignal distribution that corresponds to the $P$ (respond/ signal). That point can be found by rank ordering go-signal RTs from no-signal trials and selecting position $p n$, where $n=$ the number of RTs in the go-signal and no-signal distributions and $p=P$ (respond/signal). According to the race model, that point represents the sum of stop-signal delay plus stop-signal RT. Consequently, stop-signal RT can be estimated by subtracting the corresponding stop-signal delay (see Logan, in press; Logan \& Cowan, 1984).

The mean values for the $P$ (respond/signal) are presented in Table 5. These data were analyzed in a four-way ANOVA with Age as a between-subjects factor and Session (2, 3, and 4), StopSignal Delay $(0.2,0.4,0.6$, and 0.8$)$, and Response Compatibility Condition (compatible, neutral, and incompatible distractors) as within-subject factors. Two significant main effects were obtained. The $P$ (respond/signal) increased with increases in Stop-Signal Delay, $F(3,180)=151.5, M S_{\mathrm{e}}=0.061, p<.01$. This result is consistent with previous findings of increases in $P$ (respond|signal) with increased Stop-Signal Delays in SRT (Lappin \& Eriksen, 1966; Ollman, 1973), choice RT (Logan \& Burkell, 1986; Logan \& Cowan, 1984), and typewriting tasks (Logan, 1982). The $P$ (respond/signal) was also influenced by Response Compatibility Condition, $F(2,120)=6.44, M S_{\mathrm{e}}=$ $0.009, p<.01$. The $P$ (respond/signal) was equivalent for the compatible and neutral conditions and increased in the response incompatible condition. The $P$ (respond/signal) was .578 for the compatible distractor condition, .578 for the neutral condition, and .596 for the incompatible condition. One reasonable speculation concerning this effect is that it is more difficult to inhibit the two responses that are primed in the incompatible distractor condition than it is to inhibit a single response in the compatible and neutral conditions. The main effect of Age was not statistically significant $(p>.40)$ for $P$ (respond|signal). The estimated power for this effect was .62 .

The mean values for the stop-signal RT are presented in Table 6 for the four stop-signal delays and three response compatibility conditions for the young and old subjects. The data were analyzed in a four-way ANOVA with Age as the between-subjects factor and Session, Stop-Signal Delay, and Response Compatibility Conditions as within-subjects factors. Older subjects' stop-signal RTs were longer than those produced by young subjects, $F(1,60)=16.2, M S_{\mathrm{e}}=195,468, p<.01$. This result suggests that the old subjects took longer to implement the inhibitory or stopping process than did the young subjects.

An important question is whether the longer stop-signal RTs for the old than for the young subjects is just another example of the phenomenon of general slowing (Cerella, 1985b, 1990; Salthouse, 1985). Models of general slowing would predict an equivalent ratio difference between stop-signal RT and SRT for old and young adults. Therefore, a general slowing explanation of the age-related differences in stop-signal RTs is inconsistent with our finding of a significantly larger ratio difference (e.g., [stop-signal RT - SRT]/SRT) for the old than for the young 
subjects, $F(1,60)=6.8, M S_{\mathrm{e}}=1.08, p<.01$. The mean ratio for the old was .26 as compared with .04 for the young.

Significant main effects were also obtained for Stop-Signal Delay, $F(3,180)=9.7, M S_{\mathrm{e}}=6,617, p<.01$, and Response Compatibility factors, $F(2,120)=5.4, M S_{\mathrm{e}}=8,568, p<.01$. Stop-signal RTs were longer for the incompatible distractor condition $(275 \mathrm{~ms})$ than for the compatible and neutral conditions ( 251 and $254 \mathrm{~ms}$, respectively). Thus, it would appear that the latency of inhibitory control increases with the number of primed responses. The decrease in stop-signal RT with stopsignal delay has been previously reported (Logan, in press; Logan \& Cowan, 1984) and appears to be a consequence of variability in stop-signal RT. None of the other main effects or interactions were significant.

In summary, the analysis of the data collected in the stopping task suggests that young and old subjects were both capable of inhibiting the overt responses in the primary (response compatibility) task. This claim is supported by the lack of an Age main effect or interactions of Age with other factors in the analysis of the $P$ (respond/signal). However, the stop-signal RT measure was significantly longer for the old than for the young subjects. This effect can be interpreted as evidence that the old subjects had more difficulty controlling the stopping process than did the young subjects.

Interestingly, there has been relatively little evidence for differences in stop-signal processes across different subject populations and tasks reported in the literature. One notable exception is the report of longer stop-signal RTs and flatter $P$ (respond/signal) function for hyperactive as compared with nonhyperactive children (Schachar \& Logan, 1990; Tannock et al., 1989). Although, to our knowledge, the stopping paradigm has not been previously used with old adults, there are two distinct research domains, the study of error correction and the examination of typing skills, that are relevant to the issue of age-related differences in the control of response processes. Salthouse and colleagues have examined age-related and experience effects on a number of component processes relevant to skilled typing. In one study, Salthouse and Saults (1987) required subjects to stop typing as soon as the display was terminated and

\section{Table 6}

Mean Stop-Signal Reaction Times for the Young and Old Subjects for Each of the Stop-Signal Delays and Response Compatibility Conditions

\begin{tabular}{|c|c|c|c|c|c|c|c|}
\hline \multirow{3}{*}{$\begin{array}{l}\text { Age } \\
\text { group }\end{array}$} & \multirow{3}{*}{$\begin{array}{l}\text { Tone } \\
\text { delay }\end{array}$} & \multicolumn{6}{|c|}{ Response compatibility condition } \\
\hline & & \multicolumn{2}{|c|}{ Compatible } & \multicolumn{2}{|c|}{ Neutral } & \multicolumn{2}{|c|}{ Incompatible } \\
\hline & & $M$ & $S D$ & $M$ & $S D$ & $M$ & $S D$ \\
\hline \multirow[t]{4}{*}{ Young } & .20 & 231 & 80 & 228 & 71 & 247 & 115 \\
\hline & 40 & 209 & 67 & 207 & 59 & 223 & 108 \\
\hline & .60 & 200 & 73 & 212 & 103 & 226 & 111 \\
\hline & .80 & 186 & 72 & 175 & 54 & 220 & 118 \\
\hline \multirow[t]{4}{*}{ Old } & .20 & 316 & 96 & 321 & 124 & 349 & 153 \\
\hline & .40 & 294 & 105 & 308 & 112 & 315 & 144 \\
\hline & .60 & 291 & 113 & 295 & 117 & 311 & 136 \\
\hline & .80 & 278 & 118 & 281 & 96 & 305 & 155 \\
\hline
\end{tabular}

Note. The data are collapsed across sessions. found that young and old typists did not differ in their stopping span. In another study, Salthouse (1984) found that old typists made fewer transposition errors than did young typists. Both of these findings suggest that old subjects have at least as much control over their typing as do young subjects. Thus, at first glance, our findings appear inconsistent with those obtained by Salthouse. However, it is important to note that, in general, the old typists were also more experienced than the young typists. Thus, it is conceivable that the greater experience possessed by the old subjects might have compensated for any age-related decreases in the efficiency of inhibiting the typing responses.

This compensatory hypothesis is consistent with the error correction literature. Rabbitt (1990) asked subjects to perform a two-choice RT task and to either (a) ignore errors and continue to respond as if nothing had happened, (b) immediately correct each error by making the response that they should have made, or (c) signal an error by pressing a separate response key. Rabbitt argued, on the basis of previous research (Maylor \& Rabbitt, 1987, 1989; Rabbitt, 1979), that error detection as reflected by the slowing of RT subsequent to an incorrect response or the production of an error correction response (e.g., production of the correct response following an error) was automatic, whereas error signaling represents a more consciously controlled process. Neither the number of trials on which error detection responses were made nor the number of error trials that resulted in slowing of subsequent responses differed between young and elderly adults. However, the old subjects signaled significantly fewer errors than did the young subjects. These results suggest that some aspects of response monitoring take place automatically and that these processes appear relatively insensitive to aging. However, other aspects of response monitoring that are less thoroughly practiced such as making an error-signaling response and in the present study aborting a response that has already begun appear to be more sensitive to aging. An important question for future research is whether old adults can learn to more precisely control their stopping process, as reflected by a decrease in stop-signal RTs, with training.

\section{Negative Priming Task}

Two major issues were examined in the analysis of the data collected in the negative priming task. First, we report the results of the analyses of the prime-display data. Given that the prime display included both response compatible and incompatible distractors, these analyses give us another opportunity to examine the influence of distracting information on target processing. However, the difference in the structure of the stopping and negative priming tasks will enable us to go beyond providing a simple replication of the interference effect that was examined in the stopping task. One important difference between the tasks is the predictability of target and distractor locations. In the stopping task, both the target and distractors were located in the same positions across trials. However, in the negative priming task, target and distractor positions varied randomly over trials. Thus, we are able to contrast age-related differences in the response compatibility interference effect in nonsearch and search tasks. A second important difference between the stopping and the negative priming task is the use of location precues. In the negative priming task, the position of 
Table 7

Mean Correct Reaction Times (RTs; in milliseconds) and Error Rates for the Prime Trials in the Negative Priming Task

\begin{tabular}{|c|c|c|c|c|}
\hline \multirow[b]{3}{*}{ Age group } & \multicolumn{4}{|c|}{ Response compatibility condition } \\
\hline & \multicolumn{2}{|c|}{ Compatible } & \multicolumn{2}{|c|}{ Incompatible } \\
\hline & $M$ & $S D$ & $M$ & $S D$ \\
\hline \multicolumn{5}{|l|}{ Young } \\
\hline \multicolumn{5}{|l|}{0 -ms SOA } \\
\hline RT & 577 & 68 & 611 & 61 \\
\hline Error rate & 5.4 & 3.0 & .90 & 3.8 \\
\hline \multicolumn{5}{|l|}{$100-\mathrm{ms} \mathrm{SOA}$} \\
\hline RT & 547 & 58 & 562 & 59 \\
\hline Error rate & 5.8 & 3.2 & 7.4 & 3.5 \\
\hline \multicolumn{5}{|l|}{ 200-ms SOA } \\
\hline RT & 537 & 55 & 552 & 54 \\
\hline Error rate & 6.4 & 2.7 & 6.8 & 3.5 \\
\hline \multicolumn{5}{|l|}{ Old } \\
\hline \multicolumn{5}{|l|}{0 -ms SOA } \\
\hline RT & 747 & 104 & 780 & 95 \\
\hline Error rate & 7.2 & 5.2 & 9.4 & 5.9 \\
\hline \multicolumn{5}{|l|}{ 100-ms SOA } \\
\hline RT & 689 & 91 & 705 & 100 \\
\hline Error rate & 5.8 & 3.8 & 6.2 & 4.3 \\
\hline \multicolumn{5}{|l|}{ 200-ms SOA } \\
\hline RT & 672 & 93 & 689 & 95 \\
\hline Error rate & 6.2 & 3.4 & 5.5 & 4.6 \\
\hline
\end{tabular}

Note. The data are presented for each of the precue-display stimulus onsent asynchronies (SOAs) for the compatible and incompatible distractor conditions. The data are collapsed across the two sessions.

the target on the prime display is either cued simultaneously with display onset ( $0-\mathrm{ms} \mathrm{SOA}), 100 \mathrm{~ms}$, or $200 \mathrm{~ms}$ before the onset of the target and distractors. Thus, we examine the extent to which the young and old subjects are able to use the precue to reduce distractor interference.

The second major issue that was investigated is the influence of aging on the suppression or negative priming effect. This was examined by contrasting performance on the probe trials as a function of the strueture of the prime displays. Negative priming or suppression occurs when the RT is longer, when a prime distractor becomes a probe target, than when new targets and distractors are presented on prime and probe trials. Additionally, we examine the extent to which the spatial precues on the prime trial influence the negative priming that is observed on the probe trial. The important question here is whether prefocusing attention on the target location on the prime trial can preclude the inhibitory processes that are associated with distractor processing.

Prime trial-response compatibility analyses. Table 7 presents the mean RT and error rates for the young and old subjects for the compatible and incompatible conditions at each of the precue SOAs. The RT data were analyzed in a four-way ANOVA, with Age as a between-subjects factor and Session (1 and 2$)$, SOA (0, 100, and $200 \mathrm{~ms})$, and Response Compatibility (compatible and incompatible) as within-subjects factors. Significant main effects were obtained for Age, $F(1,60)=60.1$, $M S_{\mathrm{e}}=87,015, p<.01$; Session, $F(1,60)=157.9, M S_{\mathrm{e}}=2,742$, $p<.01$; Response Compatibility, $F(1,60)=149.3, M S_{\mathrm{e}}=485$, $p<.01$; and SOA factors, $F(2,120)=564.1, M S_{\mathrm{e}}=533, p<$ .01 . As expected, old subjects were slower than young subjects. RTs were faster in the second than in the first session. Trials with response incompatible distractors were slower than trials with response compatible distractors. RTs decreased with increasing precue SOA. The Response Compatibility $\times$ Age interaction did not attain significance $(p>.55)$. The estimated power for the incompatible-compatible age group comparison was .62 .

There was a significant two-way interaction between SOA and Response Compatibility Condition, $F(2,120)=27.8, M S_{\mathrm{e}}=$ $177, p<.01$. The difference between the compatible and incompatible conditions decreased from the 0 - to the $100-\mathrm{ms}$ SOA condition. The incompatible minus compatible RT differences were 34,16 , and $16 \mathrm{~ms}$ for the 0 -, 100-, and 200-ms SOA conditions, respectively. Interestingly, this pattern of results was obtained for both the young and old subjects. Thus, it would appear that both groups of subjects were able to take advantage of the precue information to reduce the distractor interference. In fact, a significant two-way interaction between SOA and Age, $F(2,120)=14.5, p<.01$, suggests that the old subjects were more successful in reducing their RT with increasing SOA than were the young subjects. The reduction in RT from the 0 - to the 200-ms SOA condition was $50 \mathrm{~ms}$ for the young and $83 \mathrm{~ms}$ for the old subjects. No other interactions attained statistical significance.

An ANOVA with the same structure was performed on the error rate data. Significant main effects were obtained for Session, $F(1,60)=38.5, M S_{\mathrm{e}}=0.004, p<.01 ; \mathrm{SOA}, F(2,120)=$ $34.1, M S_{\mathrm{e}}=0.001, p<.01$; and Response Compatibility factors, $F(1,60)=10.0, M S_{\mathrm{e}}=0.0002, p<.01$. Error rates decreased with Session and SOA. Error rates were higher on the incompatible than on the compatible distractor trials. SOA interacted with Response Compatibility, $F(2,120)=12.9, M S_{\mathrm{e}}=$ $0.0007, p<.01$, such that the difference between compatible and incompatible trials decreased with increases in the precue SOA. Finally, error rates decreased to a greater extent for old than for young subjects with increasing SOA, $F(2,120)=16.2$, $M S_{\mathrm{e}}=0.016, p<.01$.

In summary, the results obtained for the prime trial of the negative priming task were consistent with those obtained on the no-signal trials in the stopping task. In both cases, old and young subjects showed equivalent interference effects for both RTs and accuracies. The present analyses also suggest that old subjects benefit to at least the same extent as young subjects when a location precue is available (Hartley et al., 1990, 1992; Madden, 1983, 1986; Nissen \& Corkin, 1985).

Probe trial-negative priming analyses. Table 8 presents the mean RTs and error rate for the control and IR trials as a function of the prime-trial SOA. The RTs were calculated from trials on which both the prime and probe responses were correct. The control trials were defined as those prime-probe couplets in which the target and distractors presented on the prime trial differed from those presented on the probe trial. The IR trials were defined as those prime-probe couplets in which the distractors from the prime trial became the target on the probe trial.

The mean RT data were analyzed in a four-way ANOVA with Age as the between-subjects factor and Session (1 and 2), PrimeTrial SOA (0, 100, and $200 \mathrm{~ms})$, and Trial Type (control and IR) 
Table 8

Mean Correct Reaction Times (RTs; in milliseconds) and Error Rates for the Probe Trials in the Negative Priming Task

\begin{tabular}{|c|c|c|c|c|}
\hline \multirow[b]{3}{*}{ Age group } & \multicolumn{4}{|c|}{ Trial type } \\
\hline & \multicolumn{2}{|c|}{ Control } & \multicolumn{2}{|c|}{ Ignored repetition } \\
\hline & $M$ & $S D$ & $M$ & $S D$ \\
\hline \multicolumn{5}{|l|}{ Young } \\
\hline \multicolumn{5}{|l|}{ 0-ms SOA } \\
\hline RT & 622 & 65 & 640 & 68 \\
\hline Error rate & 7.6 & 4.7 & 8.0 & 3.4 \\
\hline \multicolumn{5}{|l|}{$100-\mathrm{ms} \mathrm{SOA}$} \\
\hline RT & 626 & 66 & 631 & 67 \\
\hline Error rate & 7.5 & 3.9 & 7.8 & 3.7 \\
\hline \multicolumn{5}{|l|}{$200-\mathrm{ms} \mathrm{SOA}$} \\
\hline RT & 635 & 65 & 634 & 67 \\
\hline Error rate & 7.7 & 3.4 & 8.3 & 3.8 \\
\hline \multicolumn{5}{|l|}{ Old } \\
\hline \multicolumn{5}{|l|}{0 -ms SOA } \\
\hline RT & 778 & 91 & 799 & 90 \\
\hline Error rate & 10.1 & 8.0 & 11.1 & 7.0 \\
\hline \multicolumn{5}{|l|}{$100-\mathrm{ms} \mathrm{SOA}$} \\
\hline RT & 767 & 89 & 782 & 88 \\
\hline Error rate & 10.7 & 6.9 & 10.8 & 7.5 \\
\hline \multicolumn{5}{|l|}{$200-\mathrm{ms} \mathrm{SOA}$} \\
\hline RT & 788 & 87 & 783 & 91 \\
\hline Error rate & 11.5 & 8.3 & 11.3 & 7.7 \\
\hline
\end{tabular}

Note. The data are collapsed across two sessions. SOA $=$ stimulus onset asynchrony.

as within-subjects factors. Significant main effects were obtained for all of the factors. Old subjects performed the task more slowly than did young subjects, $F(1,60)=68.6, M S_{\mathrm{e}}=$ $72,534, p<.01$. RT decreased from Session 1 to Session 2 , $F(1,60)=113.8, M S_{\mathrm{e}}=2,514, p<.01$. RTs decreased from the 0 - to the 100 -ms Prime-Trial SOA, $F(2,120)=18.6, M S_{\mathrm{e}}=$ $331, p<.01$. Control trials were performed more quickly than IR trials, $F(1,60)=25.3, M S_{\mathrm{e}}=485, p<.01$.

A significant two-way interaction between Trial Type and SOA, $F(2,120)=24.7, M S_{\mathrm{e}}=336, p<.01$, was also obtained. This interaction suggests that the difference between the control and the IR RT (e.g., the suppression or negative priming effect) decreased with increasing SOAs. The negative priming effect for the 0-, 100-, and 200-ms SOAs were 20, 10, and $-3 \mathrm{~ms}$, respectively. Thus, it would appear that focusing attention on the prime-trial location decreased the need for inhibiting the distractor representation. The interaction between Age and Trial Type was not significant $(p>.75)$. The estimated power for the IR-control age group comparison was .62 .

An ANOVA with the same structure was performed on the error rate data. Only two significant effects were found in this analysis. Old subjects were less accurate than were young subjects, $F(1,60)=8.6, M S_{\mathrm{e}}=0.086, p<.01$, and error rate decreased from Session 1 to Session $2, F(1,60)=57.0, M S_{\mathrm{e}}=$ $0.007, p<.01$.

These data are quite interesting in that, contrary to previous researchers (Hasher et al., 1991; McDowd \& Oseas-Kreger, 1991; Tipper, 1991), we found equivalent magnitudes of negative priming for young and old subjects. ${ }^{5}$ Furthermore, both the young and old subjects were equally capable of reducing the negative priming effect by prefocusing their attention on the target location on the prime trial. The negative priming effects for the $0-, 100-$, and $200-\mathrm{ms}$ SOA were 18,5 , and $-1 \mathrm{~ms}$, respectively, for the young and 21,15 , and $-5 \mathrm{~ms}$, respectively, for the old subjects.

This discrepancy may be explained, in part, by recent findings reported by Connelly and Hasher (1992, 1993; see also Filion et al., 1992). In their studies, subjects were required to respond to the position of a target rather than identify a target. Under these conditions, young and old subjects produced equivalent negative priming effects. The authors interpreted these findings in terms of multiple inhibitory systems, only some of which diminish in effectiveness with aging.

In an effort to examine this issue, we reanalyzed our data with respect to whether (a) the target position on the probe trial was the same as a distractor position on the prime trial or (b) the target position on the probe trial was the same as the target position on the prime trial. In the former case, the negative priming effect could occur on the basis of either location or identity suppression (e.g., on the IR trials). This is referred to as the identity-location condition. In the latter case, the negative priming effect could only occur on the basis of identity suppression. This is referred to as the identity condition. Given Connelly and Hasher's $(1992,1993)$ findings, we might expect to find equivalent negative priming effects for young and old subjects in the identity-location condition but larger negative priming effects for the young than for the old subjects in the identity condition.

Table 9 presents the mean RT and error rate data for the young and old subjects as a function of target location, trial type, and SOA. The RT data were submitted to a five-way ANOVA with Age as the between-subjects factor and SOA (0, 100 , and $200 \mathrm{~ms}$ ), Target Location (identity and identity-location), Trial Type (IR and control), and Session (1 and 2) as within-subjects factors. Significant main effects were obtained for all of these factors. Older subjects responded more slowly than young subjects, $F(1,60)=71.5, M S_{\mathrm{e}}=51,609, p<.01$. Subjects responded more quickly in Session 2 than they did in Session $1, F(1,60)=126.4, M S_{\mathrm{e}}=2,168, p<.01$. RTs decreased from the 0 - to the 100 -ms prime-trial SOA, $F(2,120)=$ $25.1, M S_{\mathrm{e}}=2,230, p<.01$. Control trials were responded to more quickly than were IR trials, $F(1,60)=58.3, M S_{\mathrm{e}}=5,630$, $p<.01$. Finally, identity-location trials were responded to more slowly than were identity trials, $F(1,60)=10.2, M S_{\mathrm{e}}=5,172, p$ $<.01$.

A significant two-way interaction was obtained between SOA and Trial Type, $F(2,120)=6.6, M S_{\mathrm{e}}=801, p<.01$. This interaction suggests that the difference between IR and control RTs decreased with increasing prime-trial SOAs. IR minus control difference RTs for the 0-, 100-, and 200-ms SOAs were 19.5, 5 , and $-6 \mathrm{~ms}$, respectively. A two-way interaction was also obtained between the Target Location and Trial Type factors, $F(1,60)=9.5, M S_{\mathrm{e}}=2,925, p<.01$, such that larger differences

\footnotetext{
s In an effort to ensure that the negative priming effect was reliable for both the young and old adults, we examined the effect separately for each group of subjects. The Trial Type factor (IR vs. control) was significant for both the young, $F(1,31)=8.6, M S_{\mathrm{c}}=161, p<.01$, and old adults, $F(1,29)=21.5, M S_{e}=324, p<.01$.
} 
Table 9

Mean Correct Reaction Times (RTs; in milliseconds) and Error Rates for the Probe Trials in the Negative Priming Task

\begin{tabular}{|c|c|c|c|c|c|c|c|c|}
\hline \multirow[b]{4}{*}{ Age group } & \multicolumn{8}{|c|}{ Trial type } \\
\hline & \multicolumn{4}{|c|}{ Identity } & \multicolumn{4}{|c|}{ Identity-location } \\
\hline & \multicolumn{2}{|c|}{ Control } & \multicolumn{2}{|c|}{ IR } & \multicolumn{2}{|c|}{ Control } & \multicolumn{2}{|c|}{ IR } \\
\hline & $M$ & $S D$ & $M$ & $S D$ & $M$ & $S D$ & $M$ & $S D$ \\
\hline \multicolumn{9}{|l|}{ Young } \\
\hline \multicolumn{9}{|l|}{0 -ms SOA } \\
\hline $\mathrm{RT}$ & 605 & 63 & 621 & 66 & 627 & 68 & 646 & 71 \\
\hline Error rate & 6.5 & 4.1 & 5.9 & 6.3 & 7.9 & 5.0 & 7.7 & 6.4 \\
\hline \multicolumn{9}{|l|}{$100-\mathrm{ms} \mathrm{SOA}$} \\
\hline RT & 600 & 59 & 600 & 61 & 633 & 66 & 642 & 70 \\
\hline Error rate & 5.3 & 3.4 & 5.9 & 4.7 & 8.2 & 4.7 & 8.4 & 5.5 \\
\hline \multicolumn{9}{|l|}{$200-\mathrm{ms}$ SOA } \\
\hline RT & 613 & 64 & 605 & 58 & 646 & 68 & 647 & 74 \\
\hline Error rate & 6.3 & 5.0 & 5.2 & 4.4 & 8.1 & 5.5 & 9.3 & 5.8 \\
\hline \multicolumn{9}{|l|}{ Old } \\
\hline \multicolumn{9}{|l|}{0 -ms SOA } \\
\hline RT & 771 & 90 & 791 & 96 & 796 & 92 & 817 & 99 \\
\hline Error rate & 10.6 & 8.4 & 11.5 & 10.3 & 11.6 & 9.4 & 12.4 & 9.6 \\
\hline \multicolumn{9}{|l|}{$100-\mathrm{ms} \mathrm{SOA}$} \\
\hline RT & 769 & 86 & 765 & 89 & 784 & 90 & 797 & 86 \\
\hline Error rate & 11.8 & 8.0 & 11.5 & 8.8 & 12.0 & 8.7 & 12.4 & 9.4 \\
\hline \multicolumn{9}{|l|}{$200-\mathrm{ms} \mathrm{SOA}$} \\
\hline RT & 797 & 94 & 788 & 98 & 805 & 92 & 798 & 93 \\
\hline Error rate & 12.3 & 7.3 & 13.2 & 8.1 & 12.8 & 9.5 & 12.6 & 8.7 \\
\hline
\end{tabular}

Note. The data are collapsed across two sessions. $I R=$ ignored repetition trials. SOA $=$ stimulus onset asynchrony.

in RT were obtained between the IR and control trials (e.g., a larger negative priming effect) in the identity-location condition than in the identity condition. This finding suggests that the negative priming effect can be separately influenced by two factors: the spatial relations between targets and distractors across trials as well as by the identity of the stimuli.

The present ANOVA was performed to determine whether our finding of a negative priming effect for the elderly subjects could be attributed to inhibition of location rather than identity of the stimuli. However, our failure to find a significant threeway interaction $(p>.75$; estimated power for the IR-control age group comparison was .62) among the Trial Type, Target Location, and Age factors indicates that the old and young subjects produced equivalent negative priming effects regardless of whether the distractor in the prime trial remained in the same position when it became a target on the probe trial. Thus, it would appear that our results provide a demonstration of inhibitory effects for old subjects in an identity-based negative priming paradigm.

An ANOVA with the same structure was performed on the error rate data. The old subjects were less accurate than the young subjects, $F(1,60)=10.9, M S_{\mathrm{e}}=0.456, p<.01$, and the IR trials were responded to less accurately than were the control trials, $F(1,60)=11.8, M S_{\mathrm{e}}=0.048, p<.01$.

In summary, there were several important findings in the negative priming analyses. First, the decrease in the negative priming effect (e.g., IR minus control RT) with increasing primetrial SOA indicates that the influence of distracting information can be reduced either (a) by inhibiting the representation of the distracting information, as is evidenced by the negative priming effect in the 0-SOA condition, or (b) through prefocusing attention on the location of the target stimulus, thereby selectively ignoring the distractors. To our knowledge the present data represent the first demonstration that the negative priming effect can be reduced by prefocusing attention on the basis of a physical cue. In fact, in a previous study (Driver \& Tipper, 1989), a negative priming effect was obtained even though subjects demonstrated successful filtering of distractors on the basis of color. However, the finding that spatial but not color precues result in reduced negative priming effects, and by inference a reduced need to inhibit the representation of the distractors, is consistent with other studies that have provided evidence for the special status of space and spatial cues in attentional processes (Garner, 1987; Kramer, Tham, \& Yeh, 1991; Nissen, 1985; Treisman \& Sato, 1990; Tsal \& Lavie, 1988). ${ }^{6}$

\footnotetext{
${ }^{6}$ It might be argued that there is a plausible alternative interpretation of our finding of a reduced negative priming effect with increasing prime-trial SOAs. Thus, although we have interpreted this effect in terms of a narrowing of attention to the target location, it might be argued that the effect is due to a reduced acuity of the distractors, brought about by a movement of the eyes to the target location, with the 100 - and 200-ms SOAs. This interpretation is certainly plausible for the 200-ms SOA trials because $400 \mathrm{~ms}$ (e.g., 200 -ms display duration) is more than sufficient time to make a $1^{\circ}$ eye movement (Carter, Obler, Woodward, \& Albert, 1983). In an effort to determine whether eye movements, rather than attentional shifts, could be responsible for the
} 
The second, and perhaps more important, finding was the equivalent negative priming effects that were obtained for the young and old subjects. The critical question here is why we obtained negative priming effects despite a number of previous reports of a lack of such effects for elderly subjects (Hasher et al., 1991; Kane et al., 1994; McDowd \& Oseas-Kreger, 1991; Stoltzfus et al., 1993; Tipper, 1991). One possibility that we have previously raised was that the negative priming effect found for the old subjects could be the result of inhibition of location rather than inhibition of distractor identity. Locationspecific negative priming effects have been previously reported for elderly subjects (Connelly \& Hasher, 1992, 1993; Filion et al., 1992). However, when we separated experimental trials on the basis of whether identity or identity-location inhibition would be possible, we found equivalent negative priming effects for old and young subjects in both conditions.

Another possible reason for the discrepancy between our study and others has been suggested in a recent review of the inhibition and aging literature. McDowd, Oseas-Kreger, and Filion (in press) have speculated that the temporal structure of the task, that is, whether prime-probe couplets are presented in a forced or self-paced manner, may influence the extent to which old adults exhibit a negative priming effect. In fact, many previous studies (Hasher et al., 1991; McDowd \& Oseas-Kreger, 1991; Tipper, 1991) that have examined age-related differences in identity-based negative priming have presented the trials in a forced-paced manner, whereas the presentation of our primeprobe couplets was self-paced. Interestingly, the negative priming studies in which subjects responded to the location rather than the identity of the targets trials were also presented in a self-paced manner (Connelly \& Hasher, 1992, 1993). Old and young subjects produced equivalent negative priming effects in these studies. Therefore, it is conceivable that previous failures to find negative priming effects for old subjects in the identity detection tasks were due to the rapid presentation of the stimuli on the forced-paced trials. Such an effect could be the result of either (a) an extended refractoriness of the inhibitory mechanism for the old subjects or (b) insufficient time for the old subjects to prepare for the selective processing of the targets. The temporal structure explanation gains some credence from a recent report by Filion et al. (1992) that old subjects showed larger negative priming effects in a self- as compared with a forcedpaced version of a location-based negative priming paradigm. However, evidence contrary to the temporal structure hypothesis has been recently provided by Kane et al. (1994), who reported a failure to find a negative priming effect for old subjects in a self-paced word identification task.

In an effort to further explore this issue, we conducted a study in which we compared 6 young and 6 old subjects in self- and

decreased negative priming effects with spatial precues, we conducted a study with 8 subjects in which the same procedures were used, with the exception that the stimulus displays were presented for $100 \mathrm{~ms}$ with a 90-ms precue-stimulus SOA. Our results were the same as those obtained in the present study. The negative priming effect diminished from the 0 - to the $90-\mathrm{ms}$ SOA condition. Thus, it would appear that the reduced negative priming effect can be interpreted in terms of attentional focusing rather than a movement of the eyes to the target location. forced-paced versions of our negative priming task. The forcedpaced version of the task was identical to the self-paced version with the exception that the intercouplet interval was fixed at $1,500 \mathrm{~ms}$. The negative priming effects were significant for both the young and old subjects in the self- and forced-paced versions of the task. Furthermore, there was no significant difference in the magnitude of the negative priming effects for either the age or task variables. The negative priming effects for the young subjects in the self- and forced-paced tasks were 18 and $19 \mathrm{~ms}$, respectively. The comparable effects for the old subjects were 18 and $21 \mathrm{~ms}$. Thus, it appears unlikely that the temporal structure hypothesis provides a viable explanation for the discrepancy in age-related negative priming effects across studies.

There are several additional hypotheses concerning the discrepancy in age-related negative priming effects that warrant some consideration. One hypothesis concerns the relationship between the negative priming effect and the level of intellectual functioning of the subjects. A reasonable speculation is that higher intellectual functioning might be associated with more efficacious inhibitory processing, particularly for the old adults. The old and young subjects who participated in our study were extremely high functioning. The mean IQ scores (Kaufman \& Kaufman, 1990) for the old and young subjects were 117.6 and 117.8 , respectively, a full standard deviation above the population mean. Young and old subjects also showed high and equivalent levels of performance on the Digit Span tasks. Finally, both the young and old subjects were well educated. The mean number of years of formal education for the young and the old subjects were 16.4 and 16.3 , respectively. Given the trend for increased education over the past several decades, the fact that the mean education level of the old subjects was that of a bachelor's degree suggests that our elderly subjects were substantially above the norm.

However, several other studies used high-functioning young and old adults, as indexed by years of education and performance on vocabulary tests, and failed to find significant negative priming effects for the old subjects (Hasher et al., 1991; Kane et al., 1994; Stoltzfus et al., 1993). However, Sullivan and Faust (1993) have recently reported significant negative priming effects for high-functioning old adults in a picture identification task. Their subjects were both well educated and possessed WAIS-R Vocabulary subtest scores that were significantly higher than the age-scaled norms. Furthermore, overall mean RTs were equivalent for the young and old subjects in the picture identification task. This is quite a remarkable finding given that the great majority of studies find substantially slower RTs for old than for young adults (Cerella, 1990; Myerson et al., 1991; Salthouse, 1992).

In an effort to examine the relationship between the level of intellectual function and inhibitory processing in our sample, we computed correlations between the subjects' negative priming scores and subscales of the Kaufman Brief Intelligence Test, the WAIS-R Digit Span subtests, and the number of years of education. Several significant correlations were obtained. A correlation of .32 was obtained between the matrices subscale of the Kaufman Brief Intelligence Test and the negative priming score, suggesting that high IQs were associated with enhancements in inhibitory processing. Significant correlations were also obtained between both the Forward and Backward Digit 
Table 10

Intertask Correlations

\begin{tabular}{|c|c|c|c|c|c|c|c|c|c|c|c|}
\hline Measure & 1 & 2 & 3 & 4 & 5 & 6 & 7 & 8 & 9 & 10 & $\begin{array}{l}\text { Trials to } \\
\text { Category } 1\end{array}$ \\
\hline Response compatibility $(\mathrm{I}-\mathrm{C}$ ) & -0.02 & 0.01 & 0.01 & 0.12 & $0.35^{* *}$ & -0.12 & 0.03 & 0.14 & 0.12 & 0.12 & 0.02 \\
\hline 1. Negative priming & - & 0.03 & 0.07 & 0.18 & $-0.28^{*}$ & -0.02 & 0.08 & -0.09 & -0.01 & -0.02 & -0.12 \\
\hline 2. Stopping slope & & - & $-0.53^{* *}$ & $-0.65^{* *}$ & 0.06 & -0.10 & -0.12 & 0.14 & 0.15 & 0.17 & 0.18 \\
\hline 3. Stopping probability & & & - & $0.44^{* *}$ & 0.01 & -0.03 & 0.16 & -0.06 & -0.09 & -0.14 & -0.08 \\
\hline 4. Stopping RT & & & & - & 0.18 & -0.15 & 0.11 & 0.08 & -0.05 & -0.11 & -0.12 \\
\hline 5. CFQ & & & & & - & $-0.32^{* *}$ & $-0.31 * *$ & $0.31^{* *}$ & $0.27^{*}$ & $0.26^{*}$ & $0.32^{* *}$ \\
\hline 6. Categories & & & & & & - & $0.66^{* *}$ & $-0.88^{* * *}$ & $-0.81^{* *}$ & $-0.75^{* *}$ & $-0.68^{* *}$ \\
\hline 7. Concept level responses & & & & & & & - & $-0.63^{* *}$ & $-0.65^{* *}$ & $-0.61 * *$ & $-0.61^{* *}$ \\
\hline 8. Total errors & & & & & & & & - & $0.87^{* *}$ & $0.85^{* *}$ & $0.68^{* *}$ \\
\hline 9. Perseverative responses & & & & & & & & & - & $0.95 * *$ & $0.71^{* *}$ \\
\hline 10. Perseverative errors & & & & & & & & & & - & $0.75^{* *}$ \\
\hline
\end{tabular}

Note. $\mathrm{I}=$ incompatible $; \mathrm{C}=$ compatible; $\mathrm{RT}=$ reaction time; $\mathrm{CFQ}=$ cognitive failures questionnaire.

${ }^{*} p<.05 .{ }^{* *} p<.01$.

Span scores and the negative priming score, .37 and .41 , respectively. Thus, subjects with larger digit spans also displayed enhanced inhibitory function.

Although the size of the correlations was only moderate, these findings are actually fairly impressive given the restricted range of the IQs obtained in our study (e.g., 102 to 136) and the fact that all of the subjects possessed IQs in the average to high range. In any event, it would appear that the relationship between general intellectual functioning and inhibition merits further examination in the future.

One additional speculation concerning the discrepancy in age-related differences in negative priming relates to the structure of the probe display. Moore (in press; see also Lowe, 1979; Neill \& Westberry, 1987; Tipper et al., 1990) has recently reported that negative priming does not occur if there is no information present on the probe trial that conflicts with the correct response. In her studies, subjects identified a target stimulus on the prime trial and attempted to ignore a partially superimposed distractor. Negative priming effects were obtained only in cases in which targets on the probe trial (e.g., targets that were distractors on the prime trial) were accompanied by a distractor or there was the expectation that a distractor would be present on the probe trial. Moore speculated that negative priming does not occur in nonconflict trials because the negative priming process, which protects the information-processing system from selecting an incorrect response, is not necessary under nonconflict situations.

Previous studies (Hasher et al., 1991; Kane et al., 1994; McDowd \& Oseas-Kreger, 1991; Stoltzfus et al., 1993; Tipper, 1991) have presented subjects with a single target and distractor on each trial that were either physically separated, distinguishable by color, or distinguishable by both color and location. However, the one previous study that has found negative priming for old adults in an identity-priming task (Sullivan \& Faust, 1993) superimposed target and distractor pictures. In our study, we presented subjects with three distractors and a target on each probe trial. Furthermore, the relative positions of these items varied randomly across trials. Thus, it would appear that selection on the probe trial might be considerably more difficult in the two identity-priming studies that have found negative prim- ing effects for old adults than in those studies that have not found such effects.

An important question for future research is whether selection difficulty is indeed an important mediating factor in agerelated differences in negative priming. Of course, an equally important question is why such a factor might produce agerelated differences in negative priming. On that account, it is conceivable that the threshold for maintaining activation of the inhibitory-based protective mechanism increases with age and therefore negative priming effects would only be expected when difficult discriminations are anticipated or encountered.

\section{Intertask Correlations}

Table 10 presents a correlation matrix for a subset of the performance measures from the CFQ, WCST, response compatibility, negative priming, and stopping tasks. These particular measures were selected because they have been previously used as indexes of inhibitory processing in their respective tasks. The correlations were computed to examine the extent to which inhibitory processes exhibited in the different tasks were independent. Age was partialed out of each of the correlations.

As can be seen from the table, the WCST measures are strongly related to each other as are the measures acquired in the stopping task. Consistent with previous studies (Tipper \& Baylis, 1987), there are significant correlations between the response compatibility measure (incompatible minus control) and the CFQ score $(r=.35)$ as well as between the negative priming measure (IR minus control) and the CFQ score ( $r=$ -.28 ). The former correlation has been interpreted as evidence that failures to successfully ignore distractors in a laboratory environment are predictive of cognitive failures in everyday activities. The latter correlation can also be interpreted as support for an association between laboratory measures of selection efficiency and attentional failures in everyday activities. In this case, it would appear that increased suppression of irrelevant information in laboratory tasks is predictive of fewer cognitive failures in extralaboratory activities. It is important to point out, however, that Kane et al. (1994) did not find significant correlations between the CFQ and measures of interference and 
inhibition for either young or old adults. However, the correlations obtained by Kane et al. were in the same direction as those obtained in our study.

Interestingly, a significant correlation was not obtained between the two laboratory measures, the response compatibility and negative priming scores, that were associated with $\mathrm{CFQ}$ scores. Thus, it appears that the response compatibility effect and negative priming effects may provide independent assessments of inhibitory function. It is important to note, however, that other researchers have reported a significant negative correlation between performance in the response compatibility task and the negative priming effect (Beech, Baylis, Smithson, \& Claridge, 1989; Tipper \& Baylis, 1987; Tipper, Bourque, Anderson, \& Brehaut, 1989; Tipper et al., 1990). This association has been interpreted as evidence for a single inhibitory process that influences performance on both the prime and probe trials. Subjects who had difficulty ignoring the distractors on the prime trial, and hence had a large response compatibility effect, displayed a small negative priming effect on the subsequent trial. Thus, it was assumed that the inhibition that was measured as the negative priming effect aided the subject in ignoring the distractors on the prime trial. Unfortunately, the single inhibitory mechanism explanation is inconsistent with a number of studies that have failed to find a significant association between the response compatibility and negative priming measures (Connelly \& Hasher, 1993; Driver \& Tipper, 1989; Kane et al., 1994; Yee, 1991). Although, at present, it is unknown why these two measures are associated in some studies and not in others, it would appear reasonable to assume that the inhibitory processes that underlie the response compatibility and negative priming effects are dissociable, at least under some conditions. This speculation is consistent with a recent proposal by Stoltzfus et al. (1993) that instead of aiding in concurrent selection, the inhibition inferred from the negative priming paradigm might help sustain attention toward a previously selected target by reducing the probability that attention will return to a previous distractor.

Significant correlations were also obtained between the CFQ score and a number of WCST measures. Subjects who reported frequent cognitive failures attained fewer categories, made fewer category level responses, took longer to attain the first category and made more errors on the WCST than subjects who reported few cognitive failures in everyday activities. The WCST measures were not associated with any of the other task measures. Thus, the fact that the WCST, response compatibility, and negative priming measures were correlated with the CFQ score but not with each other suggests that the CFQ taps a number of independent inhibitory processes.

The three measures acquired in the stopping task were strongly related to each other but not to measures on any of the other tasks. Steeper slopes for the $P$ (respond|signal) function were associated with faster stop-signal RTs and higher mean $P($ respond $\mid$ signal).

In summary, the pattern of correlations among measures acquired from the different tasks provides evidence for independent varieties of inhibitory function. However, one important and thus far unanswered question is whether the correlations among variables acquired from different tasks were low because the variables had little systematic variance. In an effort to rule out this artifact-based explanation for the obtained pattern of correlations, we assessed the reliability of the variables obtained in the response compatibility, stopping, and negative priming paradigms by computing two measures for each of the variables for each subject and calculating the correlation between these measures across subjects. The two measures were calculated by computing one measure for the odd-numbered and another measure for the even-numbered trials for each of the variables. In the case of the response compatibility and negative priming measures, the data were parsed into odd and even bins on the basis of the incompatible (response compatibility task) and IR (negative priming task) trials. We then subtracted the most temporally proximal control trials from these values to produce the difference scores. The slopes in the stopping task were computed by sorting odd and even trials, within the respective tone delay conditions (e.g., .20, .40, .60, and .80), into different bins, averaging the odd and even trials at each tone delay, and computing the two slopes. The intersubject correlations for the variables, corrected by the Spearman-Brown formula (Cronbach, 1970) for split-half reliability coefficients, were .92 for the response compatibility measure, .92 for the negative priming measure, .93 for the stopping task slope measure, .94 for the stop-signal RT measure, and .98 for the stopping task probability measure. Thus, it appears reasonable to conclude that the low correlations across tasks were not due to the unreliability of the variables. The theoretical implications of the correlation data for models of aging and attention are discussed in the subsequent section.

\section{General Discussion}

Two related issues were investigated in our study. First, we examined whether age-related inhibitory failures could be characterized as general or specific in nature. This issue was investigated by requiring subjects to perform a number of tasks from which we could derive measures of inhibitory function. Across the tasks included in our battery we found relatively limited evidence for age-related deficits in inhibitory processing. As evidenced by the stop-signal RT data, old adults were slower than young adults at aborting a physical response once it was initiated. Older adults also had more difficulty than young adults learning new rules in a categorization task as indicated by the number of perseverative errors obtained in the WCST paradigm. However, old and young adults produced equivalent response competition effects, negative priming effects, spatial precuing effects, and self-reported cognitive failures. Each of these effects has been previously interpreted in terms of inhibitory processing.

The pattern of correlations among the measures of inhibitory function obtained from the tasks in our battery also speak to the issue of the generality of inhibitory function. In general, there was little evidence for associations among measures acquired in the different tasks. Performance on a number of tasks, however, was associated with responses on the CFQ. Thus, it would appear that the CFQ is sensitive to different varieties of inhibitory function and, in particular, to those inhibitory processes that have implications for everyday behaviors. In summary, the failure to find age-related decrements in measures of inhibitory function across tasks coupled with the relative lack 
of associations among measures acquired in different tasks provide a clear answer to our first question, age-related inhibitory failures are specific rather than general in nature.

The important question at this point, however, is whether the pattern of age-related deficits in inhibitory function obtained in our study can be accommodated by a coherent theoretical framework. Previously we reviewed two proposals that have been offered to account for and predict age-related deficits in inhibitory processing. One such proposal offered by Connelly and Hasher (1993) suggests that age-related inhibitory failures will be observed to the extent that tasks require the processing of the identity of visual stimuli but not when the processing of locational information is required. The basis for this model is the distinction between what has been referred to as two separate visual pathways: the dorsal pathway, which is concerned with the processing of location, and the ventral pathway, which specializes in the detailed processing of objects (Merigan \& Maunsell, 1993; Ungerleider \& Mishkin, 1982).

Several aspects of our data are consistent with the dorsalventral model. Old and young adults displayed equivalent spatial precuing effects and location-identity negative priming effects. Given that such effects can be assumed to be mediated, to a large extent, by processing mechanisms in the dorsal visual pathway, similar patterns of performance are predicted for young and elderly adults. However, other aspects of our data are more difficult for the dorsal-ventral visual pathway model to handle. For example, both the response compatibility task and the identity negative priming judgment require the processing of aspects of the stimuli other than location. That is, the target letters need to be distinguished from the distractor letters, an operation that should clearly necessitate processing by the ventral visual pathway. Thus, the dorsal-ventral pathway model would predict age-related differences in the response compatibility and identity negative priming effects. However, the old and young adults produced equivalent patterns of performance in these paradigms. The dorsal-ventral pathway model also fails to make predictions for the WCST task and the stopping paradigm because processing in both of these tasks is mediated, in part, by a region of the brain, the frontal lobes, which is not a component of either the dorsal or ventral pathway.

Overall, the pattern of data obtained in our study is quite compatible with the frontal lobe model (Arbuckle \& Gold, 1993; Dempster, 1992; Hartley, 1993) of aging and inhibitory function. Age-related deficits in inhibitory processing were obtained in the two tasks, WCST and stopping, in which processing has been linked to frontal lobe function. Older adults had more difficulty, in the form of increased perseverative errors, than young adults learning new rules for performing the card sorting task. A number of previous studies have found that poor performance on the WCST and, in particular, perseverative errors is associated with frontal lobe dysfunction (Drewe, 1974; Heaton, 1981; Milner, 1963). Studies have also discovered that tasks that require the monitoring or coordination of several different varieties of stimulation, such as that required in the stopping paradigm, show substantial activation of components of the frontal lobes such as the anterior cingulate (Corbetta et al., 1991; Duncan, in press).

The frontal lobe model is also consistent with our failure to find age-related differences in inhibitory function in the form of the response compatibility effect, negative priming effect, and the spatial cuing effects. The information-processing activities that mediate these effects appear to be carried out, for the most part, in components of the dorsal or ventral visual pathways.

However, given previous research that has shown smaller identity-based negative priming effects (Hasher et al., 1991; Kane et al., 1994; McDowd \& Oseas-Kreger, 1991; Stoltzfus et al., 1993; Tipper, 1991) and larger response compatibility effects (Cerella, 1985a; Farkas \& Hoyer, 1980; R. Shaw, 1991) for old than for young adults, we believe that it would be premature to discount the importance of the dorsal-ventral distinction in accounting for age-related inhibitory failures. In fact, it is certainly conceivable that there are multiple inhibitory mechanisms, for example, inhibitory mechanisms subserved by the dorsal-ventral visual pathways as well as the frontal lobes, and that the integrity of these mechanisms decreases at different rates during the course of normal aging. Such a proposal is consistent with the time course of regional changes in neuroanatomy and function during aging (Scheibel \& Scheibel, 1975; T. Shaw et al., 1984).

An interesting and important question for future research is whether age-related inhibitory deficits are amenable to intervention. That is, are there methods by which age-related changes in inhibitory function might be slowed or reversed? Although we do not know of any studies that directly address this issue, there has been a good deal of recent research that has examined the efficacy of training techniques and aerobic exercise programs for improving mental functions of old adults. For example, Dustman et al. (1984; see also Hawkins, Kramer, \& Capaldi, 1992) found improvements in the performance of a number of tasks following the participation in a short-term program of aerobic exercise by a group of previously sedentary old adults. Similarly, training programs have been found to dramatically improve the performance of elderly adults on a variety of cognitive skills such as visual search (Ball, Beard, Roenker, Miller, \& Griggs, 1988), fluid intelligence (Baltes, Sowarka, \& Kliegel, 1989), memory (Murphy, Schmitt, Caruso, \& Sanders, 1987; Verhaeghen, Marcoen, \& Goossens, 1992), and dual-task processing (Baron \& Mattila, 1989; Larish, Kramer, DeAntonna, \& Strayer, 1993). Thus, this research suggests that it may be feasible to improve the inhibitory functions of the elderly through training.

\section{References}

Arbuckle, T. Y., \& Gold, D. P. (1993). Aging, inhibition and verbosity. Journal of Gerontology: Psychological Sciences, 48, 225-232.

Ball, K., Beard, B., Roenker, D., Miller, R., \& Griggs, D. (1988). Age and visual search: Expanding the useful field of view. Journal of the Optical Society of America, 5, 2210-2219.

Baltes, P., Sowarka, D., \& Kliegel, R. (1989). Cognitive training research on fluid intelligence in old age: What can older adults achieve by themselves? Psychology and Aging, 4, 217-221.

Baron, A., \& Mattila, W. (1989). Response slowing of older adults: Effects of time-limit contingencies on single and dual-task performances. Psychology and Aging, 4, 66 72 .

Beech, A., Baylis, G., Smithson, P., \& Claridge, G. (1989). Individual differences in schizotypy as reflected in measures of cognition inhibition. British Journal of Clinical Psychology, 28, 117-129.

Berg, E. (1948). A simple objective test for measuring flexibility in thinking. Journal of General Psychology, 39, 15-22. 
Birren, J. (1974). Translations in gerontology-from lab to life: Psychophysiology and speed of response. American Psychologist, 29, 805815 .

Broadbent, D., Cooper, P., FitzGerald, P., \& Parkes, K. (1982). The cognitive failures questionnaire (CFQ) and its correlates. British Journal of Clinical Psychology, 21, 1-16.

Bushnell, M., Goldberg, M., \& Robinson, D. (1981). Behavioral enhancement of visual responses in monkey cerebral cortex. I. Modulation in posterior parietal cortex related to selective visual attention. Journal of Neurophysiology, 46, 755-772.

Carter, J., Obler, L., Woodward, S., \& Albert, M. (1983). The effect of increasing age on the latency for saccadic eye movements. Journal of Gerontology, 38, 318-320.

Cerella, J. (1985a). Age-related decline in extrafoveal letter perception. Journal of Gerontology, 40, 727-736.

Cerella, J. (1985b). Information processing rates in the elderly. Psychological Bulletin, 98, 67-83.

Cerella, J. (1990). Aging and information processing rate. In J. Birren \& K. W. Schaie (Eds:), Handbook of the psychology of aging (3rd ed., pp. 201-221). San Diego, CA: Academic Press.

Chelazzi, L., Miller, E., Duncan, J., \& Desimone, R. (1993). A neural basis for visual search in inferior temporal cortex. Nature, 363, 345347.

Cohen, G. (1988). Age differences in memory for texts: Production deficiency or processing limitations? In L. Light \& D. Burke (Eds.), Language, memory and aging (pp. 171-190). Cambridge, England: Cambridge University Press.

Cohen, J. (1988). Statistical power analysis for the behavioral sciences. Hillsdale, NJ: Erlbaum.

Cohen, N., Dustman, R., \& Bradford, D. (1984). Age-related decrements in Stroop color test performance. Journal of Clinical Psychology, 40, 1244-1250.

Cohen, N., \& Eichenbaum, H. (1992). Memory, amnesia and the hippocampal system. Cambridge, MA: MIT Press.

Coles, M. G. H., Gratton, G., Bashore, T. R., Eriksen, C. W., \& Donchin, E. (1985). A psychophysiological investigation of the continuous flow model of human information processing. Journal of Experimental Psychology: Human Performance and Perception, 11, 529. 553.

Comalli, P., Wapner, S., \& Werner, H. (1962). Interference effects of Stroop color word test in childhood, adulthood, and aging. The Journal of Genetic Psychology, 100, 47-53.

Connelly, S. L., \& Hasher, L. (1992, April). Aging, interference and the inhibition of spatial location. Poster presented at the 4th Cognitive Aging Conference, Atlanta, GA.

Connelly, S. L., \& Hasher, L. (1993). Aging and the inhibition of spatial location. Journal of Experimental Psychology: Human Perception and Performance, 19, 1238-1250.

Corbetta, M., Miezin, F., Dobmeyer, S., Shulman, G., \& Petersen, S. (1991). Selective and divided attention during visual discriminations of shape, color, and speed: Functional anatomy by positron emission tomography. The Journal of Neuroscience, 11, 2383-2402.

Cronbach, L. (1970). Essentials of psychological testing (3rd ed.). New York: Harper \& Row.

De Jong, R., Coles, M., Logan, G., \& Gratton, G. (1990). Searching for the point of no return: The control of response processes in speeded choice reaction time performance. Journal of Experimental Psychology: Human Perception and Performance, 16, 164-182.

Dempster, F. N. (1992). The rise and fall of the inhibitory mechanism: Toward a unified theory of cognitive development and aging. Developmental Review, 12, 45-75.

DeSchepper, B., \& Treisman, A. (1991, November). Novel visual shapes in negative priming. Paper presented at the meeting of the Psychonomic Society, San Francisco.
Drewe, E. (1974). The effect of type and area of brain lesion on Wisconsin Card Sorting performance. Cortex, 10, 159-170.

Driver, J., \& Tipper, S. (1989). On the nonselectivity of "selective" seeing: Contrasts between interference and priming in selective attention. Journal of Experimental Psychology: Human Perception and Performance, 15, 304-314.

Duncan, J. (in press). Attention, intelligence and the frontal lobes. In M. S. Gazzangia (Ed.), The cognitive neurosciences. Cambridge, MA: MIT Press.

Dustman, R., Ruhling, R., Russell, E., Shearer, D., Bonekat, H., Shigeoka, J., Wood, J., \& Bradford, D. (1984). Aerobic training and improved neurophysiological function of older individuals. Neurobiology of Aging, 5, 35-42.

Eriksen, B., \& Eriksen, C. (1974). Effects of noise letters in the identification of target letters in a non-search task. Perception and Psychophysics, 16, 143-149.

Eriksen, C., Coles, M., Morris, L., \& O'Hara, W. (1985). An electromyographic examination of response competition. Bulletin of the Psychonomic Society, 23, 165-168.

Farkas, M., \& Hoyer, W. (1980). Processing consequences of perceptual grouping in selective attention. Journal of Gerontology, 35, 207-216.

Filion, D., McDowd, J., \& Baylis, G. (1992, April). Attention in prime locations: Inhibition and facilitation of young and old adults. Paper presented at the 4th Cognitive Aging Conference, Atlanta, GA.

Fisk, A. D., Fisher, D. L., \& Rogers, W. A. (1992). General slowing alone cannot explain age-related search effects: Reply to Cerella (1991). Journal of Experimental Psychology: General, 121, 73-78.

Fisk, A. D., \& Rogers, W. (1991). Toward an understanding of age-related memory and visual search effects. Journal of Experimental $P_{S y-}$ chology: General, 120, 131-149.

Garner, W. R. (1987). Location and color as cueing dimensions in contingent classification. Perception and Psychophysics, 41, 202-210.

Giambra, L. (1989). Task-unrelated thought frequency as a function of age: A laboratory study. Psychology and Aging, 4, 136-143.

Gur, R. C., Gur, R. E., Obrist, W. D., Skolnick, B. E., \& Reivitch, M. (1987). Age and regional cerebral blood flow at rest and during cognitive activity. Archives of General Psychiatry, 44, 617-621.

Haaland, K., Vranes, L., Goodwin, J., \& Garry, P. (1987). Wisconsin Card Sorting Test performance in a healthy elderly population. Journal of Gerontology, 42, 345-346.

Hartley, A. (1992). Attention. In F. I. M. Craik \& T. Salthouse (Eds.), Handbook of aging and cognition (pp. 3-49). Hillsdale, NJ: Erlbaum.

Hartley, A. (1993). Evidence for the selective preservation of spatial selective attention in old age. Psychology and Aging, 8, 371-379.

Hartley, A., Kieley, J., \& McKenzie, C. (1992). Allocation of visual attention in younger and older adults. Perception and Psychophysics, $52,175-185$.

Hartley, A., Kieley, J., \& Slabach, E. (1990). Age differences and similarities in the effects of cues and prompts. Journal of Experimental Psychology: Human Perception and Performance, 16, 523-537.

Hasher, L., Stoltzfus, E. R., Zacks, R. T.,\& Rypma, B. (1991). Age and inhibition. Journal of Experimental Psychology: Learning, Memory, and Cognition, 17, 163-169.

Hasher, L., \& Zacks, R. (1988). Working memory, comprehension, and aging: A review and a new view. In G. K. Bower (Ed.), The psychology of learning and motivation (Vol. 22, pp. 193-225). San Diego, CA: Academic Press.

Haug, H., Barmwater, U., Eggers, R., Fischer, D., Kuhl, S., \& Sass, N. L. (1983). Anatomical changes in aging brain: Morphometric analysis of the human prosencephalon. In J. Cerbos-Navarro \& H. I. Sarkander (Eds.), Neuropharmacology (Vol. 21, pp. 1-12). New York: Raven Press.

Hawkins, H., Kramer, A., \& Capaldi, D. (1992). Aging, exercise, and attention. Psychology and Aging, 7, 643-653. 
Heaton, R. (1981). A manual for the Wisconsin Card Sorting Test. Odessa, FL: Psychological Assessment Resources.

Houx, P., Jolles, J., \& Vreeling, F. (1993). Stroop interference: Aging effects assessed with Stroop color-word test. Experimental Aging Research, 19, 209-224.

Kane, M. J., Hasher, L., Stoltzfus, E. R., Zacks, R. T., \& Connelly, S. L. (1994). Inhibitory attentional mechanisms and aging. Psychology and Aging, 9, 103-112.

Kaufman, A. S., \& Kaufman, N. L. (1990). Kaufman Brief Intelligence Test. Circle Pines, MI: American Guidance Service.

Kausler, D., \& Hakami, M. (1982). Frequency judgments for young and elderly adults for relevant stimuli with simultaneously present irrelevant stimuli. Journal of Gerontology, 37, 438-442.

Kieley, J., \& Hartley, A. (1990, November). Early versus late inhibitory mechanisms and aging. Paper presented at the Annual Meeting of the Psychonomic Society, St. Louis, MO.

Kramer, A. F., Tham, M. P., \& Yeh, Y. Y. (1991). Movement and focused attention: A failure to replicate. Perception and Psychophysics, 50, 537-546.

LaBerge, D. (1992). Thalamic and cortical mechanisms of attention suggested by recent positron emission tomography experiments. Journal of Cognitive Neuroscience, 2, 358-372.

LaBerge, D., \& Buchsbaum, M. (1990). Positron emission tomographic measurements of pulvinar activity during an attention task. The Journal of Neuroscience, 10, 613-619.

Lappin, J., \& Eriksen, C. (1966). Use of a delayed signal to stop a visual reaction time. Journal of Experimental Psychology, 72, 805-811.

Larish, J., Kramer, A., DeAntonna, J., \& Strayer, D. (1993). Aging and dual-task training. In Proceedings of the Human Factors Society (pp. 162-166). Santa Monica, CA.

Layton, B. (1975). Perceptual noise and gain. Psychological Bulletin, $82,875-883$.

Logan, G. (1982). On the ability to inhibit complex movements: A study of typewriting. Journal of Experimental Psychology: Human Perception and Performance, 8, 778-792.

Logan, G. (in press). On the ability to inhibit thought and action: A users' guide to the stop signal paradigm. In D. Dagenbach \& T. H. Carr (Eds.), Inhibitory processes in attention, memory, and language. San Diego, CA: Academic Press.

Logan, G., \& Burkell, J. (1986). Dependence and independence in responding to double stimulation: A comparison of stop, change, and dual-task paradigms. Journal of Experimental Psychology: Human Perception and Performance, 12, 549-563.

Logan, G., \& Cowan, W. (1984). On the ability to inhibit thought and action: A theory of an act of control. Psychological Review, 91, 295327.

Loranger, A., \& Misiak, H. (1960). The performance of aged females on five nonlanguage tests of intellectual functions. Journal of Clinical Psychology, 16, 189-191.

Lowe, D. (1979). Strategies, context, and the mechanism of response inhibition. Memory \& Cognition, 7, 382-389.

Lowe, D. (1985). Further investigations of inhibitory mechanisms in attention. Memory \& Cognition, 13, 74-80.

MacLeod, C. (1991). Half a century of research on the Stroop effect: An integrative review. Psychological Bulletin, 109, 163-203.

Madden, D. (1983). Aging and distraction by highly familiar stimuli during visual search. Developmental Psychology, 19, 499-507.

Madden, J. (1986). Adult age differences in the attentional capacity demands of visual search. Cognitive Development, 1, 335-363.

Maylor, E., \& Hockey, R. (1985). Inhibitory component of externally controlled covert orienting in visual space. Journal of Experimental Psychology: Human Perception and Performance, 11, 777-787.

Maylor, E., \& Hockey, R. (1987). Effects of repetition on the facilitatory and inhibitory components of orienting in visual space. Neuropsychologia, 25, 51-54.

Maylor, E., \& Rabbitt, P. (1987). Effect of alcohol and practice on choice reaction time. Perception and Psychophysics, 42, 465-475.

Maylor, E., \& Rabbitt, P. (1989). Relation between rate of preparation for, and processing of, an event requiring a choice response. Quarterly Journal of Experimental Psychology, 41, 47-62.

McDowd, J., \& Filion, D. (1992). Aging, selective attention, and inhibitory processes: A psychophysiological approach. Psychology and Aging, 7, 65-71.

McDowd, J., \& Oseas-Kreger, D. (1991). Aging, inhibitory processes, and negative priming. Journal of Gerontology: Psychological Sciences, 46, 340-345.

McDowd, J., Oseas-Kreger, D., \& Filion, D. (in press). Inhibitory processes in cognition and aging. In F. Dempster \& C. Brainerd (Eds.), New perspectives on interference and inhibition in cognition. San Diego, CA: Academic Press.

Merigan, W., \& Maunsell, J. (1993). How parallel are the primate visual pathways? Annual Review of Neuroscience, 16, 369-402.

Milner, B. (1963). Effects of different brain lesions on card sorting. $A r$ chives of Neurology, 9, 90-100.

Moore, C. M. (1994). Negative priming depends on probe-trial conflict: Where has all the inhibition gone? Perception and Psychophysics, 56, 133-147.

Murphy, M., Schmitt, F., Caruso, M., \& Sanders, R. (1987). Metamemory in older adults: The role of monitoring in serial recall. Psychology and Aging, 2, 331-339.

Myerson, J., Hale, S., Wagstaff, D., Poon, L., \& Smith, G. (1991). The information loss model: A mathematical theory of age-related cognitive slowing. Psychological Review, 97, 475-487.

Neill, W. T. (1977). Inhibitory and facilitatory processes in selective attention. Journal of Experimental Psychology: Human Perception and Performance, 3, 444-450.

Neill, W. T. (1989). Lexical ambiguity and context: An activation-suppression model. In D. S. Gorfein (Ed.), Resolving semantic ambiguity (pp. 63-83). New York: Springer-Verlag.

Neill, W. T., \& Valdes, L. (1992). The persistence of negative priming: Steady state or decay? Journal of Experimental Psychology: Learning, Memory, and Cognition, 18, 565-576.

Neill, W. T., \& Westberry, R. (1987). Selective attention and supression of cognitive noise. Journal of Experimental Psychology: Learning, Memory, and Cognition, 13, 327-334.

Nissen, M. (1985). Accessing features and objects: Is location special? In M. Posner \& O. Marin (Eds.), Attention and performance XI (pp. 205-219). Hillsdale, NJ: Erlbaum.

Nissen, M., \& Corkin, S. (1985). Effectiveness of attentional cueing in older and younger adults. Journal of Gerontology, 40, 185-191.

Ollman, R. (1973). Simple reactions with random countermanding of the "go" signal. In S. Kornblum (Ed.), Attention and performance IV (pp. 571-581). San Diego, CA: Academic Press.

Osman, A., Kornblum, S., \& Meyer, D. (1986). The point of no return in choice reaction time: Controlled and ballistic stages of response preparation. Journal of Experimental Psychology: Human Perception and Performance, 12, 243-258.

Pan, K., \& Eriksen, C. (1993). Attentional distribution in the visual field during same-different judgments as assessed by response competition. Perception and Psychophysics, 53, 134-144.

Posner, M. (1992). Attention as a cognitive and neural system. Current Directions in Psychological Science, 1, 11-15.

Posner, M., \& Cohen, Y. (1984). Components of visual orienting. In H. Bouma \& D. Bouwhuis (Eds.), Attention and performance $X$ (pp. 531-556). Hillsdale, NJ: Erlbaum.

Posner, M., \& Petersen, S. (1990). The attention system of the human brain. Annual Review of Neuroscience, 13, 24-42. 
Posner, M., Rafal, R., Choate, L., \& Vaughan, J. (1985). Inhibition of return: Neural basis and function. Cognitive Neuropsychology, 2, 211-228.

Posner, M., Walker, J., Friedrich, F., \& Rafal, R. (1987). How do the parietal lobes direct covert attention? Neuropsychologia, 25, 135145.

Rabbitt, P. (1965). An age decrement in the ability to ignore irrelevant information. Journal of Gerontology, 20, 233-236.

Rabbitt, P. (1979). How old and young subjects monitor and control responses for accuracy and speed. British Journal of Psychology, 70, 305-311.

Rabbitt, P. (1990). Age, IQ and awareness, and recall of errors. Ergonomics, $11,1291-1305$.

Rogers, W., \& Fisk, A. D. (1991). Age-related differences in the maintenance and modification of automatic processes: Arithmetic Stroop interference. Human Factors, 33, 45-56.

Salthouse, T. (1984). Effects of age and skill in typing. Journal of Experimental Psychology: General, 113, 345-371.

Salthouse, T. (1985). Speed of behavior and its implications for cognition. In J. E. Birren \& K. W. Schaie (Eds.), Handbook of the psychology of aging (pp. 400-426). New York: Van Nostrand Reinhold.

Salthouse, T. (1992). Mechanisms of age-cognition relations in adulthood. Hillsdale, NJ: Erlbaum.

Salthouse, T., \& Saults, J. (1987). Multiple spans in transcription typing. Journal of Applied Psychology, 72, 187-196.

Schachar, R., \& Logan, G. (1990). Impulsivity and inhibitory control in normal development and childhood psychopathology. Developmental Psychology, 26, 710-720.

Scheibel, M., \& Scheibel, A. (1975). Structural changes in the aging brain. In H. Brody, D. Harmon, \& J. Ordy (Eds.), Aging (Vol. 1, pp. 11-37). New York: Raven Press.

Scialfa, C., Kline, D., \& Lyman, B. (1987). Age differences in target identification as a function of retinal location and noise level: Examination of the useful field of view. Psychology and Aging, 2, 14-19.

Shallice, T., \& Burgess, P. (1991). Deficits in strategy application following frontal lobe damage in man. Brain, 114, 727-741.

Shaw, R. (1991). Age-related increases in the effects of automatic semantic activation. Psychology and Aging, 6, 595-604.

Shaw, T., Mortel, K., Meyer, J., Rogers, R., Hardenberg, J., \& Cutaia, M. (1984). Cerebral blood flow changes in benign aging and cerebrovascular disease. Neurology, 34, 855-862.

Stoltzfus, E., Hasher, L., Zacks, R., Ulivi, M., \& Goldstein, D. (1993). Investigations of inhibition and interference in younger and older adults. Journal of Gerontology: Psychological Sciences, 48, 179-188.

Stroop, J. R. (1935). Studies of interference in serial verbal reactions. Journal of Experimental Psychology, 18, 643-662.

Sullivan, M. P., \& Faust, M. E. (1993). Evidence for identity inhibition during selective attention in old adults. Psychology and Aging, 8, 589598.

Tannock, R., Schachar, R., Carr, R., Chajczyk, D., \& Logan, G. (1989). Effects of methylphenidate on inhibitory control in hyperactive children. Journal of Abnormal Child Psychology, 17, 473-491.

Tipper, S. (1985). The negative priming effect: Inhibitory priming by ignored objects. The Quarterly Journal of Experimental Psychology, $37,571-590$.
Tipper, S. (1991). Less attentional selectivity as a result of declining inhibition in older adults. Bulletin of the Psychonomic Society, 29, 45-47.

Tipper, S., \& Baylis, G. (1987). Individual differences in selective attention: The relation of priming and interference to cognitive failure. Personality and Individual Differences, 8, 667-675.

Tipper, S., Bourque, T., Anderson, S., \& Brehaut, J. (1989). Mechanisms of attention: A developmental study. Journal of Experimental Child Psychology, 48, 353-378.

Tipper, S., Brehaut, J., \& Driver, J. (1990). Selection of moving and static objects for the control of spatially directed attention. Journal of Experimental Psychology: Human Perception and Performance, 16, 492-504.

Tipper, S., \& Cranston, M. (1985). Selective attention and priming: Inhibitory and facilitatory effects of ignored primes. Quarterly Journal of Experimental Psychology, 37A, 591-611.

Tipper, S., \& Driver, J. (1988). Negative priming between pictures and words in a selective attention task: Evidence for semantic processing of ignored stimuli. Memory \& Cognition, 16, 64-70.

Treisman, A., \& Sato, S. (1990). Conjunction search revisited. Journal of Experimental Psychology: Human Perception and Performance, 16. 459-478

Tsal, Y., \& Lavie, N. (1988). Attending to color and shape: The special role of location in selective visual processing. Perception and Psychophysics, 44, 15-21.

Ungerleider, L., \& Mishkin, M. (1982). Two cortical visual systems. In D. Ingle, M. Goodale, \& R. Mansfield (Eds.), Analysis of visual behavior (pp. 549-586). Cambridge, MA: MIT Press.

Verhaeghen, P., Marcoen, A., \& Goossens, L. (1992). Improving memory performance in the aged through mnemonic training: A metaanalytic study. Psychology and Aging, 7, 242-251.

Warren, L. R., Butler, R. W., Katholi, C. R., \& Halsey, J. H. (1985). Age differences in cerebral blood flow during rest and during mental activation measurements with and without monetary incentive. Journal of Gerontology, 40, 53-59.

Wechsier, D. (1981). Wechsler Adult Intelligence Scale-Revised. New York: Psychological Corporation.

Welford, A. T. (1952). The psychological refractory period and timing of high speed performance: A review and a theory. British Journal of Psychology, 43, 2-19.

Whelihan, W., \& Lesher, E. (1985). Neuropsychological changes in frontal functions with aging. Developmental Neuropsychology, 1, 371380 .

Wright, L., \& Elias, J. (1979). Age differences in the effects of perceptual noise. Journal of Gerontology, 34, 704-708.

Yee, P. (1991). Semantic inhibition of ignored words during a figure classification task. The Quarterly Journal of Experimental Psychology, 43, 127-153.

Zacks, R., \& Hasher, L. (in press). Directed ignoring: Inhibitory regulation of working memory. In D. Dagenbach \& T. Carr (Eds.), Inhibitory mechanisms in attention, memory, and language. San Diego, CA: Academic Press.

Received August 20,1993

Revision received January 31, 1994 Accepted January 31, 1994 